\title{
LA CONCESIÓN DIRECTA DE SUBVENCIONES
}

\author{
ANTONIO BUENO ARMIJO' \\ Universidad de Córdoba \\ antonio.bueno@uco.es
}

\author{
Cómo citar/Citation \\ Bueno Armiio, A. (2017). \\ La concesión directa de subvenciones. \\ Revista de Administración Pública, 204, 269-312. \\ doi: https://doi.org/10.18042/cepc/rap.204.10
}

\section{Resumen}

La Ley 38/2003 General de Subvenciones estableció hace ya casi quince años que las Administraciones públicas españolas únicamente pueden conceder subvenciones a través de un procedimiento de concurrencia competitiva. Solo se previeron tres excepciones en las que se admite la concesión directa de subvenciones. Sin embargo, la forma en que se han interpretado y aplicado tales excepciones por la Administración ha dado lugar a que las subvenciones directas sean mucho más frecuentes de lo esperado. Asimismo, las leyes autonómicas han creado excepciones adicionales para evitar el procedimiento de concurrencia competitiva. El presente artículo profundiza en esta situación y analiza la legalidad y constitucionalidad de tales interpretaciones y leyes.

\section{Palabras clave}

Subvenciones; procedimiento de concurrencia competitiva; procedimiento de concesión directa; subvenciones nominativas.

1 Profesor titular de Derecho Administrativo. Grupo de Investigación de la Junta de Andalucía SEJ-196. Proyecto DER2015-67695-C2-1-P (MINECO/FEDER, UE). Orcid.org/0000-0002-6487-1142. Agradezco a Juan Diego Arenas Muńoz sus enriquecedores comentarios a una primera versión de este trabajo. 


\section{Abstract}

Almost fifteen years ago, Subsidies General Law 38/2003 imposed that every Spanish Public Administration could only grant subsidies through a competitive selection process. Just three exceptions were provided in order to allow Public Administrations to directly grant subsidies without following such a competitive selection process. Nevertheless, the way in which those exceptions have been interpreted and applied by Public Administrations have made direct subsidies far more common than expected. Furthermore, regional laws have created additional exceptions to avoid the competitive selection process. This paper delves into the issue and analyzes the lawfulness and constitutionality of those interpretations and laws.

\section{Keywords}

Subsidies; competitive selection process; direct grant process; nominative subsidies. 


\section{SUMARIO}

I. INTRODUCCIÓN: EL LADO OSCURO DE LAS SUBVENCIONES Y LA ADVERTENCIA DE LAOCONTE. II. CARACTERÍSTICAS DEL PROCEDIMIENTO DE CONCESIÓN DIRECTA DE SUBVENCIONES: 1. La ausencia de publicidad, concurrencia y, muy especialmente, competición o rivalidad entre los solicitantes. 2. El carácter extraordinario del procedimiento de concesión directa y su aplicación en supuestos tasados. 3. El carácter básico de las normas reguladoras del procedimiento de concesión directa. III. SUBVENCIONES DIRECTAS PREVISTAS EN EL ARTÍCULO 22 DE LA LEY GENERAL DE SUBVENCIONES: 1. Subvenciones previstas nominativamente en los presupuestos. 2. Subvenciones directas establecidas en norma con rango de ley. 3. Subvenciones directas excepcionales concedidas por razones de interés público, social, económico o humanitario. IV. SUPUESTOS DE CONCESIÓN DIRECTA DE SUBVENCIONES AL MARGEN DEL ARTÍCULO 22.2 DE LA LEY GENERAL DE SUBVENCIONES: 1. La concesión directa de subvenciones financiadas con cargo a fondos de la Unión Europea. 2. La concesión directa de subvenciones en materia de cooperación internacional. 3. La concesión directa de subvenciones de facto. 4. La concesión directa de subvenciones a través de convenios de colaboración. 5. La concesión de subvenciones en concurrencia competitiva basada únicamente en criterios temporales. 6. La concesión de subvenciones en «concurrencia no competitiva». V. CONCLUSIONES.

«Equo ne credite, Teucri! Quidquid id est, timeo Danaos et dona ferentes» (¡No os fieis del caballo, troyanos! Sea lo que sea, temo a los griegos incluso cuando traen regalos). Advertencia del sacerdote troyano Laoconte.

VIrgILIO, Eneida (libro II, 49).

\section{INTRODUCCIÓN: EL LADO OSCURO DE LAS SUBVENCIONES Y LA ADVERTENCIA DE LAOCONTE}

La actividad administrativa de fomento entraña riesgos para los ciudadanos. Es un hecho del que se ha advertido desde hace tiempo y sobre cuyos peligros, sin embargo, conviene insistir, porque la actividad administrativa 
de fomento sigue estando rodeada de un falso «halo de bondad», que la hace pasar por una actividad intrínsecamente favorable o, cuando menos, inocua para los derechos e intereses de los ciudadanos.

Este halo de bondad se deriva, seguramente, del hecho de que la Administración se valga de medidas favorables para intentar convencer a sus beneficiarios de que adopten ciertas conductas que satisfacen el interés general, sin imponérselas ni exigírselas, y del hecho de que tales beneficiarios sean quienes puedan decidir si aceptan las ventajas o no, asumiendo las conductas vinculadas a ellas o renunciando a las obligaciones asumidas cuando lo estimen oportuno. En efecto, nada malo ni peligroso parece que puede haber para nadie en aceptar una ventaja de la Administración en atención a una conducta que las dos partes consideran beneficiosa y a la que puede renunciar en cualquier momento, limitándose a devolver la ventaja recibida. Pero no es así. Igual que de los griegos, de la Administración debe desconfiarse incluso cuando trae regalos.

Como actuación de fomento prototípica, también la subvención pública se ha visto rodeada de este engañoso halo de bondad, lo que permitió que durante mucho tiempo su régimen jurídico no estuviese bien definido o que ni siquiera se considerase relevante para el derecho administrativo ${ }^{2}$. Por cuanto ahora interesa, en relación con la concesión de subvenciones, basta apuntar que históricamente fue frecuente que no existiese una separación clara entre el establecimiento de la subvención y la concesión de la subvención. Los ciudadanos tomaban la iniciativa

2 Al comienzo de su imprescindible trabajo, G. Fernández Farreres (1983), La subvención: concepto y régimen jurídico, Madrid: Instituto de Estudios Fiscales (págs. 27 y ss.), daba cuenta del abandono de la figura por parte de la doctrina, el legislador y la jurisprudencia, debido al "carácter voluntario y no imperativo» y la "naturaleza graciable» con que se presentaban las subvenciones. Y de cómo esa situación había dado lugar a que se descuidaran en este ámbito garantías básicas para los ciudadanos, como el sometimiento de la actividad de la Administración al principio de legalidad o al control judicial. Treinta años después, y a pesar de la aprobación de la Ley 38/2003, General de Subvenciones, volvía a denunciar la misma situación de abandono en G. Fernández Farreres (2012), «Subvenciones y ayudas económicas en tiempos de crisis», en $R E D A, 154$ (págs. 30-33). En esa línea se enmarcaban también las alertas tempranas sobre la importancia de extender a las subvenciones algunos principios constitucionales básicos, como el de igualdad, dadas por J. L. Martínez López-Muñiz (1985), «Subvenciones e igualdad. STS 3a 28 de mayo de 1985, y STC 2a, 39/1989, 16 de febrero», en REDA, 65 (págs. 119-129), y C. Albiñana García-Quintana (1984), "Criterios constitucionales sobre la subvención pública», en Presupuesto y Gasto público, 21 (pág. 206). Este riesgo de discriminación y sus consecuencias en el mercado interior son, de hecho, la base de todo el régimen jurídico de las ayudas de Estado del derecho de la Unión Europea establecido en los arts. 107-109 TFUE y en su normativa de desarrollo. 
de dirigirse a la Administración para solicitarle la concesión de subvenciones que aún no estaban ni previstas ni creadas y, si la Administración lo estimaba oportuno, procedía a la concesión de estas subvenciones ad hoc, creadas expresamente para la ocasión y que con la ocasión morían. Subvenciones que se concedían directamente a sus solicitantes, casi sin tramitar procedimiento y de las que, con razón, se afirmaba su carácter discrecional y casi graciable ${ }^{3}$, al tiempo que se lamentaba el escaso control judicial que podía ejercerse sobre las mismas.

El resultado de esta práctica era una política de subvenciones rogadas, construida "de abajo arriba", frecuentemente improvisada y con escasa o nula planificación por parte de la Administración. No obstante, sus verdaderos riesgos se cifraban en prácticas aun más peligrosas, como la aparición de relaciones clientelares y de grupos privilegiados, la concesión de financiación pública a actividades de escaso o nulo interés público y la falta de transparencia y publicidad de todo ello. Lo menos malo que se puede decir de esta forma de proceder es que no ayudaba a evitar la creación de un caldo de cultivo en el que podían desarrollarse prácticas corruptas. Aun a riesgo de acabar como él, hay que insistir con Laoconte: de la Administración, como de los griegos, debe desconfiarse incluso cuando trae regalos.

Como reacción a esta indeseable situación, la Ley 38/2003 General de Subvenciones (en adelante, LGS) reguló minuciosamente el establecimiento de subvenciones, como paso previo y distinto a su otorgamiento. Además de distinguir entre establecimiento y concesión de la subvención, la LGS introdujo en el establecimiento tres trámites bien diferenciados: la aprobación del plan estratégico de subvenciones, la notificación previa a la Comisión Europea y la aprobación de las bases reguladoras. Por centrarnos solo en el último de estos requisitos, la obligación de aprobar las bases reguladoras de concesión de las subvenciones con carácter previo a su otorgamiento (art. 9.2 LGS) permite garantizar la existencia de una norma ad hoc que regule tanto el procedimiento de concesión cuanto la relación jurídico-subvencional resultado del otorgamiento. Con esta separación entre establecimiento y concesión de las subvenciones se obliga a la Administración a introducir una cierta racionalidad y planificación en su actividad subvencional y, mucho más importante, a establecer con claridad las normas que regularán cada una de sus actuaciones, aumentando las posibilidades de control ${ }^{4}$.

3 J. L. Villar Palasí (1954), «Las técnicas administrativas de fomento y de apoyo al precio político», en RAP, 14 (pág. 79); J. M. Gimeno Feliú (1995), «Legalidad, transparencia, control y discrecionalidad de las medidas de fomento del desarrollo económico (Ayudas y subvenciones)», en RAP, 137 (pág. 180).

4 J. R. Fernández Torres (2005), «El establecimiento de subvenciones», en G. Fernández Farreres (dir.), Comentario a la Ley General de Subvenciones, Cizur Menor: Thomson-Civitas (págs. 265 y ss). 
Sin embargo, el riesgo de imprevisión, impulsividad o, en el peor de los casos, clientelismo en la concesión de subvenciones no quedaba plenamente conjurado con la mera (aunque importantísima) distinción entre establecimiento y otorgamiento. Por ello, y con buen criterio, el legislador básico también expresó la necesidad de que la concesión de subvenciones se hiciera, con carácter general, a través de un procedimiento de concurrencia competitiva. Es decir, un procedimiento que el propio legislador define como aquel en el cual:

La concesión de las subvenciones se realiza mediante la comparación de las solicitudes presentadas, a fin de establecer una prelación entre las mismas de acuerdo con los criterios de valoración previamente fijados en las bases reguladoras y en la convocatoria, y adjudicar, con el límite fijado en la convocatoria dentro del crédito disponible, aquellas que hayan obtenido mayor valoración en aplicación de los citados criterios (art. 22.1 LGS).

La LGS no inventa el procedimiento de concurrencia competitiva, antes llamado "concurso", pero sí pone fin a la preferencia por el procedimiento de concesión directa, presente hasta ese momento en nuestro ordenamiento 5 . Se trata de una medida complementaria a la distinción entre establecimiento y otorgamiento, que presenta otras ventajas adicionales:

- permite garantizar un mayor respeto al principio de igualdad entre los ciudadanos en el acceso a los privilegios públicos, evitando discriminaciones injustificadas;

- permite garantizar una asignación más racional y eficiente de los recursos, siempre escasos, de la Administración, por cuanto hace posible elegir

5 El art. 86.6.b. 50 Real Decreto Legislativo 1091/1988 por el que se aprobó el Texto Refundido de la Ley General Presupuestaria establecía: «Cuando la finalidad o naturaleza de la subvención así lo exija, su concesión se realizará por concurso». Al interpretar este precepto, la jurisprudencia consideró que del mismo parecía derivarse que el procedimiento de concesión en concurrencia competitiva era «un sistema residual» frente al sistema de concesión directa de subvenciones. Entre otras muchas, STS de 24 de febrero de 2004 (recurso 5191/1999, ponente: González González). No obstante, cabe precisar que una década antes de la aprobación de la LGS se había incluido en nuestro ordenamiento una norma que apostaba por la concesión de subvenciones en régimen de concurrencia competitiva con carácter general, aunque solo en relación con la Administración General del Estado. Véanse arts. 1.1 y 2.1 del Real Decreto 2225/1993, de 17 de diciembre, Reglamento para la concesión de subvenciones públicas. 
la opción que mejor satisface los intereses generales con menor consumo de recursos, que será aquella que reciba mejor valoración;

- finalmente, permite garantizar la publicidad y la transparencia de la actividad administrativa, con los saludables beneficios que ello suele conlle$\operatorname{var}^{6}$.

Pero la imposición del procedimiento de concesión en concurrencia competitiva para el otorgamiento de subvenciones y el destierro de las subvenciones directas también entrańa algunos inconvenientes. El principal, seguramente, es que el procedimiento de concurrencia competitiva impide que la Administración pueda establecer subvenciones directas en las que se prevea que todo aquel que se encuentre en una determinada situación o reúna ciertos requisitos pueda recibir una, de modo que cada solicitante sea considerado individualmente, sin tener en cuenta a los demás.

Este tipo de subvenciones directas son frecuentísimas y parecen especialmente aceptables, e incluso deseables, en el caso de ayudas con finalidad social. Es decir, la estrategia de elegir al más eficiente de los solicitantes, a aquel que puede realizar mejor la actividad de que se trate con el mismo dinero (público) que los demás, parece muy adecuada cuando se trata, por ejemplo, de actividades económicas. Pero ¿̇tiene sentido establecer una concurrencia competitiva entre todos los solicitantes de ayudas para la adquisición de vehículos eléctricos con el fin de elegir a los mejores de entre ellos? ¿No estaría justificado, en este caso, conceder la ayuda a todos los que reunieran ciertos requisitos, sin más trámite y sin necesidad de establecer una competición ni una subsiguiente prelación entre ellos?

Pero, por otro lado, el carácter escaso de los recursos públicos y el mandato constitucional de realizar una «asignación equitativa» de ellos que responda «a los

6 En este sentido, y destacando además las mayores posibilidades de control judicial cuando el procedimiento de concesión es en concurrencia competitiva, G. Fernández Farreres, La subvención: concepto y régimen jurídico, cit. (págs. 662 y ss.). También J. C. Laguna de Paz (2005), «El otorgamiento de subvenciones», en G. Fernández Farreres (dir.), Comentario a la Ley General de Subvenciones, cit. (págs. 333-334).

7 Véase Real Decreto 617/2017, de 16 de junio, por el que se regula la concesión directa de ayudas para la adquisición de vehículos de energías alternativas, y para la implantación de puntos de recarga de vehículos eléctricos en 2017 (Plan MOVEA 2017), cuyas ayudas, de acuerdo con su preámbulo, «se establecen como un derecho del peticionario que reúna las condiciones para su concesión, es decir, no concurre con ningún otro para obtenerlas, ya que por el mero hecho de realizar el comportamiento establecido en la norma y cumplir las condiciones y los requisitos exigidos, se deberá conceder la subvención». 
criterios de eficiencia y economía» (art. 31.2 CE), ¿no obligaría a plantearse si es conforme a derecho el otorgamiento directo e indiferenciado de subvenciones, sin atender a las características de cada beneficiario, simplemente porque reúnan ciertos requisitos? Desde esta perspectiva, la concesión directa de subvenciones no solo podría ser contraria a nuestro ordenamiento, sino socialmente injusta ${ }^{8}$.

Se trata de un debate políticamente complejo, lleno de trampas y espejismos, entre los que no es el menor la ilusoria distinción entre ayudas con fines sociales y ayudas con fines económicos, que hemos insinuado? ${ }^{9}$ Sin embargo, no es la finalidad de este trabajo terciar en dicho debate, sino constatar que el legislador tomó una decisión clara al respecto y lo dio por cerrado, con todo lo que ello conlleva ${ }^{10}$.

En efecto, la LGS, en términos muy taxativos, estableció que el otorgamiento de subvenciones debía hacerse, con carácter general y ordinario, mediante un procedimiento de concurrencia competitiva. El legislador, sin embargo, consciente de que esta regla podría resultar en ocasiones inconveniente para los intereses generales, también previó tres supuestos, tasados, en los que resulta posible acudir a la concesión directa de subvenciones. Se trata de los supuestos recogidos en el art. 22.2 LGS, a los que debe sumarse un cuarto previsto en la disposición adicional decimoctava LGS en materia de cooperación internacional.

Importa asimismo destacar que esta opción del legislador de favorecer el procedimiento de concesión de subvenciones en concurrencia competitiva,

8 El debate está además viciado por una visión errónea del deber de solidaridad social. Si la Administración considerase que todo aquel que se encuentra en una determinada situación debe recibir una subvención determinada, pero ello no resultara posible dada la inevitable situación de escasez de medios con que cuenta la Administración, deberían arbitrarse los mecanismos para que la ayuda se destinase a quien más la necesitara de entre todos los solicitantes. Lo contrario, lejos de servir a la solidaridad social, acabaría produciendo el perverso efecto de no atender al más necesitado, sino al más avisado.

9 Por seguir con el ejemplo propuesto: ¿la compra de un vehículo constituye una actividad económica o social? En relación con la artificiosa distinción entre subvenciones a la economía y subvenciones con finalidad social, A. Bueno Armijo (2013), El concepto de subvención en el ordenamiento jurídico español, Bogotá: Universidad Externado de Colombia (págs. 125-131).

10 En última instancia, el debate sobre la conveniencia de utilizar uno u otro procedimiento de concesión de subvenciones supone una traslación a este ámbito de la teoría general de la adjudicación administrativa de recursos escasos. En particular, resulta aquí particularmente relevante la distinción entre procedimientos de admisión y procedimientos de adjudicación. Véase, por todos, J. Elster (1995), Justicia Local. De qué modo las instituciones distribuyen bienes escasos y cargas necesarias, Barcelona: Gedisa. 
marginando su concesión directa hasta convertirla en excepcional, se ha impuesto a todas las administraciones públicas al dotar de carácter básico al art. 22 LGS. De este modo, se garantiza un tratamiento común de todos los ciudadanos que pretenden ser beneficiarios de subvenciones ante todas las administraciones públicas.

Casi quince años después de su entrada en vigor, es un momento adecuado para realizar una revisión del modelo impuesto por la LGS. Por una parte, para resolver las dudas interpretativas que la aplicación de la nueva normativa ha ido suscitando. Por otra parte, para analizar las reticencias que, como era previsible, las administraciones públicas han mostrado frente al nuevo modelo y los modos de reacción frente a él que han ido desplegando. Reticencias y reacciones, por cierto, que en no pocas ocasiones han sido apoyadas o encabezadas por los propios legisladores autonómicos, generando serias dudas sobre la constitucionalidad de algunas de sus medidas.

\section{CARACTERÍSTICAS DEL PROCEDIMIENTO DE CONCESIÓN DIRECTA DE SUBVENCIONES}

Las subvenciones otorgadas mediante concurrencia competitiva y las subvenciones otorgadas mediante concesión directa son iguales. El art. 2 LGS, al definir qué se entiende por subvención a los efectos de la ley, no distingue entre ambos tipos de subvenciones. No se trata, por tanto, de dos tipos de subvenciones distintas, sino de dos procedimientos distintos de concesión. Porque, en efecto, en ambos casos debe seguirse un procedimiento.

El hecho de que se hable de "concesión directa» no significa que no deba tramitarse un procedimiento para acordar dicha concesión: la concesión directa de subvenciones, como todo acto administrativo, se encuentra procedimentalizada (art. 34.1 LPAC, in fine). Lo que se quiere indicar con la expresión de "concesión directa», más modestamente, es que no se seguirá el procedimiento ordinario o de concurrencia competitiva. Esto es, se pretende sugerir la idea (no plenamente correcta, como veremos) de que todo solicitante que reúna los requisitos marcados por la norma reguladora correspondiente, recibirá la subvención, lo que en ningún caso ocurriría en las subvenciones otorgadas mediante procedimiento de concurrencia competitiva, en las que el cumplimiento de los requisitos da lugar, únicamente, a la admisión en el procedimiento, sin prejuzgar el resultado final de este.

Resulta, en todo caso, necesario profundizar en cuáles son las características que definen el procedimiento de concesión directa de subvenciones, distinguiéndolo del procedimiento de concurrencia competitiva. 


\section{LA AUSENCIA DE PUBLICIDAD, CONCURRENCIA Y, MUY ESPECIALMENTE, COMPETICIÓN O RIVALIDAD ENTRE LOS SOLICITANTES}

En primer lugar, el legislador caracteriza el procedimiento de concesión directa de manera negativa. Esto es, diciendo lo que este procedimiento no es. De acuerdo con la exposición de motivos $\$ .3$ de la LGS, el procedimiento de concesión directa se caracteriza "por la no exigencia del cumplimiento de los principios de publicidad y concurrencia». No obstante, esta afirmación exige una explicación, dado que las subvenciones directas pueden respetar, en ocasiones, el principio de concurrencia y, desde luego, siempre respetan el principio de publicidad.

En relación con el principio de concurrencia, debe aclararse que el elemento que permite distinguir entre concurrencia competitiva y concesión directa no es la falta de concurrencia, sino la ausencia de competición entre los solicitantes y la correlativa ausencia de comparación entre sus solicitudes. Es decir, en la concesión directa el otorgamiento de subvenciones a cada beneficiario se hace sin tener en cuenta a los demás. Lo relevante en el procedimiento de concesión directa no es la ausencia de "concurrencia», puesto que nada obsta a que pueda haber más de un beneficiario y que, consecuentemente, haya una convocatoria pública a la que puedan concurrir todos los solicitantes que lo deseen. El criterio determinante es la ausencia de "competición» entre ellos: todos y cada uno de los solicitantes serán beneficiarios de la correspondiente subvención simplemente con cumplir los requisitos marcados por la norma, con independencia de que haya o deje de haber otros solicitantes y de sus posibles méritos, dado que ellos también recibirán su correspondiente subvención atendiendo exclusivamente a sus propias características y no a las de los demás ${ }^{11}$.

La ausencia de competición o rivalidad entre los solicitantes y la correlativa ausencia de comparación entre sus respectivas solicitudes explica que, aunque se produzca una concurrencia pública, cada solicitud puede ser resuelta individualmente, a medida que se va presentando. Esta resolución individualizada resultaría absolutamente inviable en el caso de concurrencia competitiva, dado que, hasta que no se hubiera cerrado el plazo de presentación, sería imposible conocer todas las solicitudes presentadas para proceder a su comparación, resolver cuáles deben situarse en los primeros puestos de

11 Es decir, «habrá concurrencia, pero no comparación entre solicitudes, que es lo que caracteriza la concurrencia competitiva», J. Pascual García (2016), Régimen jurídico de las subvenciones públicas, Madrid: BOE (pág. 274). 
la lista de prelación y, consecuentemente, designar a los solicitantes que las presentaron como beneficiarios de la subvención.

Del mismo modo, la ausencia de competición entre solicitantes y de comparación entre solicitudes conlleva que no sea necesario establecer en las bases reguladoras los «criterios objetivos de otorgamiento de la subvención y, en su caso, [la] ponderación de los mismos» (art. 17.3.e LGS) que, sin embargo, sí son imprescindibles en el caso de subvenciones otorgadas en concurrencia competitiva.

Asimismo, y nuevamente a despecho de lo que se afirma en la exposición de motivos $\$ .3$ de la LGS, tampoco la ausencia de publicidad es el elemento que caracteriza al procedimiento de concesión de subvenciones. Para empezar, en todos aquellos procedimientos de concesión directa en los que haya concurrencia, será necesario dar la oportuna publicidad a fin de que los potenciales interesados puedan presentar sus solicitudes. Es cierto que no siempre habrá publicidad de la convocatoria, porque no siempre habrá convocatoria. No obstante, en todos los supuestos previstos en el art. 22.2 LGS en los que se admite la concesión directa de subvenciones habrá una norma (muchas veces incluso con rango de ley) que dé cobertura a la subvención correspondiente y que, como no puede ser de otra forma, tendrá que ser objeto de publicación en el Diario Oficial correspondiente. Asimismo, las subvenciones otorgadas mediante concesión directa deberán incluirse, exactamente igual que las subvenciones otorgadas en concurrencia competitiva, en la Base de Datos Nacional de Subvenciones a los efectos de dar cumplimiento al mandato de transparencia y publicidad impuesto por el legislador (arts. 20 LGS y 8.1.c Ley 19/2013, de 9 de diciembre, de transparencia, acceso a la información pública y buen gobierno).

\section{EL CARÁCTER EXTRAORDINARIO DEL PROCEDIMIENTO DE CONCESIÓN DIRECTA Y SU APLICACIÓN EN SUPUESTOS TASADOS}

En segundo lugar, el procedimiento de concesión directa se define por su carácter extraordinario, por su excepcionalidad frente al procedimiento de concurrencia competitiva, que constituye el procedimiento normal y ordinario. De acuerdo con este carácter excepcional, el legislador ha tasado los casos en los que será posible acudir a él, en lugar de al procedimiento ordinario de concesión en concurrencia competitiva, en el art. 22.2 LGS ${ }^{12}$.

12 El art. 2.3 RD 2225/1993 previó ya ciertas ayudas a las que no les resultaría de aplicación el procedimiento de concesión en concurrencia competitiva, destacando, expresamente, las «ayudas y subvenciones que resulten de una asignación nominativa contenida en las normas de rango legal». A su vez, este artículo se inspiraba en el 
Parece clara la voluntad del legislador de que solo quepa la concesión directa de subvenciones en los tres supuestos previstos en el art. 22.2 LGS. De acuerdo con la exposición de motivos $\$ .3$ LGS, el procedimiento de concesión directa es «aplicable únicamente en los supuestos previstos en la ley». Así cabría deducirlo también a contrario sensu del art. 22.1 LGS, al referirse expresamente al procedimiento de concesión en concurrencia competitiva como "el procedimiento ordinario", lo que implica que la concesión directa es un procedimiento extraordinario. Y con total claridad y rotundidad se expresa el art. 55.2 Real Decreto 887/2006, de 21 de julio, por el que se aprueba el Reglamento de la LGS (en adelante, RGS) al afirmar que: «Las subvenciones solo podrán concederse en forma directa en los casos previstos en el artículo 22.2 de la Ley».

Debe advertirse, sin embargo, que el legislador incluyó en la disposición adicional decimoctava una categoría completa de subvenciones que también podrán ser objeto de concesión directa al margen de lo dispuesto en el art. 22.2 LGS. Se trata de las subvenciones de cooperación internacional que sean desarrollo de la política exterior del Gobierno y cuya naturaleza resulte incompatible con los principios de "publicidad o concurrencia». También de ellas nos ocuparemos en un epígrafe posterior.

Junto con su carácter tasado, el carácter excepcional del procedimiento de concesión directa conllevaría, finalmente, que estos casos en los que resulta posible la concesión directa de subvenciones deberán interpretarse, en principio, restrictivamente.

\section{EL CARÁCTER BÁSICO DE LAS NORMAS REGULADORAS DEL PROCEDIMIENTO DE CONCESIÓN DIRECTA}

En tercer lugar, y aunque no se trate propiamente de una característica del procedimiento de concesión, sino de las normas que regulan dicho procedimiento, es oportuno recordar que estas tienen carácter parcialmente básico. Es decir, el carácter extraordinario del procedimiento (art. 22.2 LGS) y el carácter tasado de los supuestos en los que es posible acudir al procedimiento de concesión directa (art. 55.2 RGS) tienen naturaleza básica. En ambos casos, por

art. 86.6.b.2 Real Decreto Legislativo 1091/1988 TRLGP, en el que se establecía que no era necesario respetar el principio de publicidad «cuando las ayudas o subvenciones tengan asignación nominativa en los Presupuestos Generales del Estado o su otorgamiento y cuantía resulten impuestos para la Administración en virtud de normas de rango legal». Es en estos preceptos donde puede situarse el precedente inmediato de la regulación contenida en el art. 22.2 LGS. 
cierto, a sugerencia del Consejo de Estado ${ }^{13}$. Asimismo, el Tribunal Constitucional ha confirmado que el carácter básico del art. 22 LGS resulta conforme con la Constitución ${ }^{14}$.

De este modo, el legislador autonómico no puede ampliar las causas que permiten conceder subvenciones de manera directa en lugar de mediante el procedimiento ordinario de concurrencia competitiva. Hacerlo supondría ir en contra de la voluntad expresa del legislador básico e incurrir en inconstitucionalidad. De hecho, cabe afirmar que el legislador básico incluso introdujo alguna de estas causas pensando, únicamente, en el legislador autonómico, como se verá al analizar el supuesto recogido en el art. 22.2.a LGS.

A pesar de ello, varios legisladores autonómicos no han tenido empacho en realizar interpretaciones más que extensivas de los supuestos de concesión directa de subvenciones del art. 22.2 LGS y otros, abiertamente, han decidido crear

13 El carácter básico del art. 22 LGS fue sugerido por el Consejo de Estado que, con acierto, entendió que de esta forma se podía "garantizar a los administrados un tratamiento común ante todas las administraciones públicas, como exige el art. 149.1.18 a de la Constitución». Dictamen del Consejo de Estado no 1756/2003, de 26 de junio de 2003, \$.IV.A).1. Por su parte, el carácter básico del art. 55.2 RGS responde también a la sugerencia realizada por el Consejo de Estado, quien señaló su íntima vinculación con el art. 22 LGS, cuyas previsiones entendió que «son, en esencia, las mismas». Dictamen del Consejo de Estado 800/2006, de 22 de junio de 2006, \$.V.D)1. La STC 130/2013, de 4 de junio de 2013 (ponente: Aragón Reyes), confirmó el carácter básico de este precepto al vincularlo con el régimen jurídico de las administraciones públicas (art. 149.1.18 CE) «puesto que, por un lado, orienta imperativamente las relaciones entre aquellas y los ciudadanos que pretendan ser beneficiarios de las correspondientes subvenciones asegurándoles un tratamiento común y, por otro, persigue que se hagan efectivos los principios básicos del gasto público o actividad subvencional de las administraciones públicas [igualdad, publicidad, concurrencia, objetividad, transparencia, eficacia, eficiencia, asignación equitativa de los recursos (art. 31.2 CE)]» (FJ 10.a). Crítico con esta sentencia y sus «efectos recentralizadores», aunque sean en beneficio de todos los ciudadanos, C. Aymerich Cano (2013), «Subvenciones y Estado Autonómico. Crítica de la última jurisprudencia constitucional», en RVAP, 97 (septiembre-diciembre), págs. 253-256. En relación con las importantes innovaciones introducidas por esta STC en la distribución de competencias entre Estado y CC. AA. en materia de subvenciones, A. Bueno Armijo (2015), «La distribución de competencias entre Estado y Comunidades Autónomas en materia de subvenciones y la irrupción de las "actividades jurídicas típicas de la Administración" y los "procedimientos administrativos comunes singulares" en la doctrina constitucional», en M. Rebollo Puig, M. López Benítez y E. Carbonell Porras (coords.), Régimen jurídico básico de las Administraciones públicas, Madrid: Iustel (págs. 63-84). 
supuestos nuevos y distintos en los que sus respectivas administraciones pueden conceder subvenciones sin acudir al procedimiento ordinario de concurrencia competitiva. Todo ello también será objeto de análisis en el epígrafe IV.

\section{SUBVENCIONES DIRECTAS PREVISTAS EN EL ARTÍCULO 22 DE LA LEY GENERAL DE SUBVENCIONES}

\section{SUBVENCIONES PREVISTAS NOMINATIVAMENTE EN LOS PRESUPUESTOS}

De acuerdo con el art. 22.2.a LGS, no será necesario tramitar el procedimiento de concesión ordinario en concurrencia competitiva para el otorgamiento de aquellas subvenciones que hayan sido «[...] previstas nominativamente en los Presupuestos Generales del Estado, de las Comunidades Autónomas o de las Entidades Locales, en los términos recogidos en los convenios y en la normativa reguladora de estas subvenciones».

Aparentemente, se trata de un régimen único y homogéneo, común a las tres administraciones territoriales. Sin embargo, existen notables diferencias entre el caso del Estado y las comunidades autónomas, por un lado, y las entidades locales, por otro.

En efecto, en el caso del Estado y de las comunidades autónomas, el sujeto competente para aprobar el presupuesto (y crear, por tanto, las subvenciones nominativas) es distinto del sujeto competente para establecer subvenciones con carácter general. En el primer caso, es la Asamblea Legislativa correspondiente; en el segundo, la Administración General del Estado o la Administración autonómica respectiva.

El objetivo del legislador, seguramente, era reservar a las Asambleas Legislativas la posibilidad de acordar la concesión de subvenciones a sujetos concretos como manifestación de decisiones políticas. No debe verse aquí, necesariamente, nada turbio ni contrario a derecho. Aunque no siempre sean la mejor herramienta para ello, lo cierto es que las subvenciones pueden servir como instrumento de redistribución de la riqueza o de configuración de un determinado modelo de sociedad, lo que tiene un contenido abiertamente político. Asimismo, pueden preverse ciertos hechos o acontecimientos singulares (unos juegos olímpicos, una efeméride nacional, una exposición universal) a los que se desee apoyar económicamente por entender que satisfacen intereses generales y para los que no tenga sentido aprobar una convocatoria de subvenciones en tanto que ya se sabe que son únicos en su especie y que, por tanto, serían los únicos posibles beneficiarios. En tales casos, parece plenamente razonable que la subvención se prevea directamente en los presupuestos y con 
carácter nominativo. Al menos, cuando no esté prevista su continuidad a lo largo del tiempo ${ }^{15}$.

Debe destacarse además que, a diferencia de lo que acontece en el supuesto previsto en el art. 22.2.c LGS, las Asambleas Legislativas no tienen límites para decidir a quién se conceden estas subvenciones. Esto es, no es necesario que en las actividades que deseen financiar directamente concurran especiales «razones de interés público, social, económico o humanitario». Como mucho, y a lo sumo, a este tipo de decisiones de las Asambleas Legislativas podrán oponerse los límites que puedan derivarse de ciertos principios constitucionales, como el de igualdad o el de interdicción de la arbitrariedad, de difícil control en la práctica ${ }^{16}$.

En todo caso, el carácter público y deliberativo del procedimiento de aprobación de los presupuestos y la obligación de publicarlos garantizan que la inclusión de subvenciones nominativas en ellos será también pública y objeto de escrutinio.

Sin embargo, el caso de las entidades locales es muy diferente. En ellas no existe, propiamente, diferencia entre el sujeto que aprueba el presupuesto y el que establece las subvenciones al aprobar sus bases reguladoras: en ambos casos, la persona jurídica es única, así como el órgano competente, el Pleno de la Corporación. Únicamente varían los procedimientos para adoptar uno y otro tipo de decisión. El resultado tiene algo de incoherente: la Administración General del Estado o las administraciones autonómicas solo podrán crear subvenciones directas cuando concurran los requisitos del art. 22.2.c LGS, del que nos ocuparemos luego, pero del que ya hemos adelantado que es más restrictivo que el art. 22.2.a LGS. Sin embargo, las entidades que integran la Administración local, además de la posibilidad de acudir al art. 22.2.c LGS en los mismos términos que las demás administraciones, tienen la vía, mucho más amplia y sin restricciones, de acudir al art. 22.2.a LGS. Esto es, son abrumadoramente mayores las limitaciones impuestas a las administraciones

15 Menos justificables resultan las subvenciones nominativas que se prevén, año tras año, a favor de los mismos sujetos y para los mismos motivos. Por ejemplo, las subvenciones nominativas previstas cada año en los Presupuestos Generales del Estado para la financiación del transporte público regular de viajeros de Madrid, Barcelona y las Islas Canarias. Estas aportaciones dinerarias constituyen, en realidad, simples dotaciones presupuestarias y no subvenciones. Sin embargo, la disposición adicional centésima uno, de la Ley 3/2017, de 27 de junio, de Presupuestos Generales del Estado para 2017, justifica expresamente su concesión «al amparo de lo dispuesto en el artículo 22.2. y 28 de la Ley 38/2003, de 17 de noviembre, General de Subvenciones», lo que resulta rechazable.

16 J. Pascual García (2016: 275-276). 
estatal y autonómicas que a las administraciones locales para la concesión directa de subvenciones. La situación, seguramente, es el resultado de la falta de previsión del legislador básico, quien debería revisarla: la concesión de subvenciones nominativas casi sin límite alguno, como decisión política, puede ser un privilegio del legislador, no de la Administración, y menos aún, si cabe, de la Administración local.

Justamente por estos motivos, debe rechazarse la posibilidad de que puedan establecerse subvenciones nominativas a través de modificaciones presupuestarias ${ }^{17}$. En efecto, las modificaciones presupuestarias permiten introducir cambios en los presupuestos aprobados por la Asamblea correspondiente por parte de la Administración encargada de su ejecución (para el caso de la Administración General del Estado, véanse arts. 61-63 LGP). Por lo tanto, si se admitiera el establecimiento de una subvención nominativa mediante una modificación presupuestaria, se estaría permitiendo, justamente, que fuera la Administración, y no la Asamblea correspondiente, quien pudiera decidir otorgar estas subvenciones directas ${ }^{18}$. La excepción, una vez más, vendría determinada por las administraciones locales ${ }^{19}$.

También por estos mismos motivos debe rechazarse tajantemente que otras administraciones distintas de las expresamente mencionadas en el

17 Expresamente en contra de esta posibilidad, P. J. Collado Beneyto (2009), Comentario a la Ley General de Subvenciones y a su Reglamento, Valencia: Tirant lo Blanch (págs. 495-496).

18 En este sentido, el art. 52.3 LGP, al regular las transferencias de créditos (una de las posibles modificaciones presupuestarias), establece que: «En ningún caso, las transferencias podrán crear créditos destinados a subvenciones nominativas salvo que sean conformes con lo dispuesto en la Ley General de Subvenciones...». Aunque la redacción no es todo lo clara que sería deseable, lo cierto es que el artículo permite que la Administración cree subvenciones nominativas mediante una transferencia de crédito. No obstante, la exigencia de que dicha creación sea "conforme con lo dispuesto en la Ley General de Subvenciones» obliga a entender que deberán reunirse los requisitos marcados en el art. 22.2.c LGS, único caso en que la Administración puede acordar, por sí misma, la concesión directa de subvenciones sin acudir al procedimiento de concesión en concurrencia competitiva.

19 En su caso, nuevamente, resulta posible el establecimiento de subvenciones nominativas en todos aquellos supuestos en los que las modificaciones presupuestarias son competencia del Pleno y se someten para su aprobación a los mismos trámites que el presupuesto (caso de las transferencias entre distintas áreas de gasto, suplementos de crédito o créditos extraordinarios). Solo cabrá excluir la posibilidad de establecer subvenciones nominativas cuando las modificaciones presupuestarias sean competencia de la Alcaldía (caso de las transferencias de crédito entre áreas de gasto de la misma naturaleza). 
art. 22.2.a LGS puedan hacer uso de esta posibilidad de conceder directamente subvenciones nominativas a través de sus presupuestos. Así, debe rechazarse, por ejemplo, que las universidades públicas puedan prever subvenciones nominativas en sus presupuestos con el fin de concederlas directamente y sin acudir al procedimiento ordinario de concurrencia competitiva ${ }^{20}$.

Sin perjuicio de las diferencias señaladas, en los tres casos la previsión de las subvenciones nominativas en los correspondientes presupuestos generales debe cumplir unos requisitos. En efecto, no todas las previsiones presupuestarias nominativas son subvenciones. Será necesaria una identificación suficientemente precisa, no bastando la existencia de meras previsiones genéricas referidas a grupos de posibles beneficiarios o líneas genéricas de ayudas. Para el caso del Estado, el art. 22.2.a.2 LGS expresamente dispone que en el estado de gasto correspondiente de los Presupuestos Generales del Estado debe aparecer determinada, al menos, la dotación presupuestaria y el beneficiario $^{21}$. Junto a estos datos, la clasificación funcional y económica de

20 Y ello, aun cuando, en el caso de las Universidades, a diferencia de lo que acontece en las entidades locales, el órgano competente para aprobar el presupuesto, que es el Consejo Social (art. 14.2.20 Ley Orgánica 6/2001, de 21 de diciembre, de Universidades), es distinto del órgano competente para el establecimiento de subvenciones mediante la aprobación de sus bases reguladoras, que es el Consejo de Gobierno (art. 15.1 Ley Orgánica 6/2001, de 21 de diciembre, de Universidades).

21 La redacción actual de este precepto viene dada por la disposición final décimo segunda de la Ley 17/2012, de 27 de diciembre, de Presupuestos Generales del Estado para el año 2013. Es de lamentar, sin embargo, que esta nueva redacción no incluyera también la obligación de indicar expresamente que la partida se corresponde con una subvención nominativa, usando justamente esta expresión. La ausencia de esta indicación expresa dificulta notablemente la localización de este tipo de subvenciones, pues de la simple lectura de los presupuestos es imposible deducir si una partida presupuestaria vinculada a un sujeto identificado con su nombre constituye una subvención o responde a cualquier otro título jurídico ( $v$. gr., pagos adeudados por cualquier forma de responsabilidad contractual o extracontractual). En este sentido, resulta mucho más satisfactoria y digna de emulación la configuración de las subvenciones nominativas realizada, al menos desde 2007, por el Parlamento de La Rioja. Como ejemplo más reciente, la Ley 2/2017, de 31 de marzo, de presupuestos generales de la Comunidad Autónoma de La Rioja para el año 2017, dispone que «las subvenciones tendrán carácter nominativo [...] cuando se cumplan los dos requisitos siguientes:

a) Que tanto el beneficiario como la actividad, proyecto o comportamiento singular a financiar figuren nominativamente en los créditos de los estados numéricos de esta ley.

b) Que la subvención aparezca recogida en el anexo III de subvenciones nominativas de esta ley». 
la partida debería permitir determinar el objeto de la subvención, con lo que la Administración tendría los datos suficientes para proceder a su ejecución. Ello sin perjuicio de que el objeto y los detalles de la relación jurídica subvencional queden plenamente determinados en el instrumento de concesión correspondiente.

\section{SUBVENCIONES DIRECTAS ESTABLECIDAS EN NORMA CON RANGO DE LEY}

De conformidad con el art. 22.2.b LGS, también pueden concederse directamente, sin necesidad de acudir al procedimiento ordinario de concurrencia competitiva, aquellas subvenciones "cuyo otorgamiento o cuantía venga impuesto a la Administración por una norma de rango legal...».

Este supuesto, en realidad, constituye un mero acto de deferencia del legislador estatal hacia el legislador autonómico, puesto que su única utilidad es habilitar a este último a hacer algo que, de otro modo, tendría vedado hacer: conceder o prever la concesión de subvenciones sin seguir el procedimiento de concurrencia competitiva establecido como obligatorio por el art. 22.1 LGS, de carácter básico. En efecto, en la medida en que el Estado no está vinculado por sus propias normas básicas, nada obstaría a que el legislador estatal concediera una subvención de manera directa a través de una norma con rango de ley, haciendo caso omiso a lo dispuesto por él mismo en el art. 22.1 LGS. Y no solo sería posible que el legislador estatal concediera subvenciones «singulares». Del mismo modo, nada obstaría tampoco a que una norma sectorial estatal con rango de ley estableciera las excepciones que estimara oportunas al procedimiento de concesión ordinario o en concurrencia competitiva en el sector que regulara.

Sin embargo, la situación es muy distinta para el legislador autonómico. Este último sí se encuentra vinculado por el carácter básico de la normativa estatal, cuyo contenido no puede transgredir. En consecuencia, si la propia normativa básica no hubiera establecido la posibilidad de que el legislador autonómico pudiera prever excepciones a la concesión ordinaria de subvenciones en concurrencia competitiva, este no podría preverlas. De ahí que este supuesto únicamente se dirija al legislador autonómico y no al legislador estatal. Asimismo, las posibilidades de excepción concedidas al legislador autonómico son mucho más limitadas que aquellas de las que goza el legislador estatal, en la medida en que aquel no puede limitarse a realizar una remisión en bloque a la Administración, posibilidad que sí está al alcance del legislador estatal, como veremos.

El art. 22.2.b LGS impone tanto requisitos formales como materiales para poder hacer uso de esta posibilidad de concesión directa de subvenciones. 
Desde un punto de vista formal, la concesión directa de la subvención debe venir acordada en una norma con rango de ley. A falta de mayores precisiones, deben aceptarse por tanto todo tipo de leyes, incluyendo leyes ordinarias, leyes orgánicas o leyes de aprobación de presupuestos generales ${ }^{22}$.

Igualmente, deben admitirse otras normas con rango de ley, como decretos legislativos o decretos ley ${ }^{23}$. E incluso los Reglamentos de las Cámaras legislativas ${ }^{24}$.

Desde un punto de vista material, la norma con rango de ley no solo debe prever la concesión directa de la subvención, sino que debe entrar a regularla por sí misma. De este modo, no deben entenderse incluidas en este supuesto las simples habilitaciones legales a que la Administración pueda establecer un régimen de ayudas en un determinado sector. El art. 22.2.b LGS es claro al establecer que el otorgamiento debe «venir impuesto» a la Administración ${ }^{25}$.

22 Aunque pueda resultar paradójico, además de prever subvenciones nominativas, las leyes de presupuestos generales también pueden establecer subvenciones de concesión directa al amparo del art. 22.2.b LGS. Véase, en este sentido, la disposición adicional centésimo décimo sexta de la Ley 3/2017, de 27 de junio, de Presupuestos Generales del Estado para 2017, en cuyo apartado tercero se establece que: "Las ayudas del Ministerio de Energía, Turismo y Agenda Digital al coste de la promoción de la generación de la electricidad a partir de fuentes renovables [...] se podrán conceder de forma directa, tal y como establece el artículo 22.2.b) de la Ley 38/2003, de 17 de noviembre, General de Subvenciones...».

A modo de ejemplo, el Real Decreto Ley 1/2011, de 11 de febrero, de medidas urgentes para promover la transición al empleo estable y la recualificación profesional de las personas desempleadas, estableció la concesión directa de las llamadas «ayudas económicas de acompańamiento» creadas y reguladas por esa misma norma. El mismo régimen se mantuvo por las normas que prorrogaron este programa, $v$. gr., Real Decreto Ley 23/2012, de 24 de agosto, por el que se prorroga el programa de recualificación profesional de las personas que agoten su protección por desempleo.

Los Reglamentos de las Cámaras Legislativas son, precisamente, las normas que se encargan de regular uno de los ejemplos paradigmáticos de subvenciones concedidas directamente y sin necesidad de tramitar el procedimiento ordinario de concesión en concurrencia competitiva: las subvenciones otorgadas a los grupos políticos que actúan en tales Cámaras. Estas subvenciones, sin embargo, están excluidas del ámbito de aplicación de la Ley General de Subvenciones (art. 4.d LGS), lo que genera no pocas dificultades en su régimen jurídico. Sobre todo ello, véase el excelente trabajo de Á. González-Juliana (2014), «Las subvenciones a los grupos políticos en las Asambleas Legislativas españolas», en Revista Digital de Derecho Administrativo, 11 (págs. 77-113).

25 No parece, por tanto, que puedan aceptarse como ejemplos de subvenciones concedidas al amparo de este supuesto ayudas como las previstas en el art. 20 de la Ley 6/1977, de 4 de enero, de fomento de la minería, a las que expresamente se refiere E. Moreu 
El legislador tiene que establecer por sí mismo las subvenciones que se concederán de manera directa, así como algunos elementos esenciales de su régimen jurídico: su objeto, sus potenciales beneficiarios, su cuantía, el procedimiento para su concesión. Lo contrario constituiría una deslegalización en favor de la Administración de una previsión básica, posible para el legislador estatal, pero no para el legislador autonómico.

No obstante, es también admisible que el legislador remita a la Administración la concreción de algunos de estos elementos. Así ocurre, paradigmáticamente, con las ayudas concedidas a estudiantes de los distintos niveles educativos, cuya concesión directa se establece en la disposición adicional novena de la Ley 24/2005, de 18 de noviembre, de reformas para el impulso de la productividad, en la que se fijan ciertos criterios para su concesión y el cálculo de sus cuantías, dejando su concreción última a la Administración, lo que se realiza anualmente ${ }^{26}$.

En el extremo opuesto, nada de lo dicho obsta a que la norma con rango de ley llegue a concretar no solo la cuantía y el objeto de la subvención, sino incluso a sus beneficiarios, identificándolos individualmente. Esto es, la previsión nominativa de subvenciones no está reservada, en modo alguno, a las leyes de presupuestos generales a las que hace referencia el art. 22.2.a LGS, antes analizado, sino que puede producirse también en cualquier norma con rango de ley al amparo del art. 22.2.b LGS ${ }^{27}$.

Carbonell (2005), «Procedimiento de concesión y gestión de las subvenciones», en F. López Ramón (coord.), Comentarios a la Ley General de Subvenciones, Valencia: Tirant lo Blanch (pág. 91). Dicho artículo se limita a indicar que la Administración "podrá conceder» ciertas ayudas a las empresas mineras, pero sin que en ningún caso la concesión de tales ayudas "venga impuesta» a la Administración ni, menos aún, deba hacerse necesariamente sin tramitar un procedimiento de concurrencia competitiva. Véase Real Decreto 726/2017, de 21 de julio, por el que se establecen los umbrales de renta y patrimonio familiar y las cuantías de las becas y ayudas al estudio para el curso 2017-2018. El mismo fenómeno ocurre también con las tradicionales ayudas concedidas a los agricultores por el Estado para el pago de la prima del seguro agrario combinado. La disposición adicional segunda de la Ley 87/1978, de 28 de diciembre, de seguros agrarios combinados, dispone que: «Las aportaciones del Estado al importe global de las primas a satisfacer por los agricultores se concederán de forma directa a los agricultores, tal y como establece el artículo 22.2.b) [LGS]...». En relación con su cuantía, el art. 11 de la misma Ley 87/1978 establece unos criterios para su cálculo y unos límites máximos y mínimos, siendo definitivamente fijados en normas de desarrollo.

27 Por ejemplo, la disposición transitoria única de la Ley 43/2015, de 9 de octubre, del Tercer Sector de Acción Social estableció un listado nominativo de entidades a las que concedió, directamente y por sí misma, diversas subvenciones para el sostenimiento económico-financiero de sus estructuras centrales. 


\section{SUBVENCIONES DIRECTAS EXCEPCIONALES CONCEDIDAS POR RAZONES DE INTERÉS PÚBLICO, SOCIAL, ECONÓMICO O HUMANITARIO}

$\mathrm{El}$ art. 22.2.c LGS también admite, en último lugar, que puedan concederse directamente: "Con carácter excepcional, aquellas otras subvenciones en que se acrediten razones de interés público, social, económico o humanitario, u otras debidamente justificadas que dificulten su convocatoria pública».

La expresa referencia al «carácter excepcional» con que se pueden conceder directamente subvenciones en el marco de este artículo ha dado lugar a que estas subvenciones reciban frecuentemente el nombre de «subvenciones excepcionales». Sin embargo, la práctica administrativa desarrollada desde la aprobación de la LGS no permite afirmar que estas subvenciones hayan tenido nada de excepcionales.

A diferencia de los otros dos supuestos contenidos en el art. 22.2 LGS, antes vistos (subvenciones nominativas previstas en los presupuestos generales y subvenciones previstas en norma con rango de ley), la posibilidad de conceder subvenciones directas contenida en este art. 22.2.c LGS no se dirige al legislador, sino a la Administración, aunque su articulación resulta algo problemática en el caso de las entidades locales ${ }^{28}$. De este modo, el art. 22.2.c LGS contiene la única vía a la que pueden acudir las administraciones públicas (salvo la anomalía, ya indicada, en las administraciones locales) para escapar de la obligación de que todas las subvenciones que se concedan en España lo sean a través del procedimiento de concurrencia competitiva. Esto explicaría, en buena medida, los denodados esfuerzos que han realizado muchas administraciones públicas para extender los límites de este supuesto e intentar calzar en él todo tipo de situaciones. Han pretendido con ello mantener las potestades de concesión directa de subvenciones de las que disfrutaban casi ilimitadamente antes de la aprobación de la LGS.

No debe perderse de vista la situación de partida a la que se enfrentó la LGS y a la que se hizo referencia en la introducción de este trabajo: un modelo de subvenciones "de abajo arriba», falto de planificación administrativa, en el que los privados tomaban la iniciativa de solicitar ayudas a los poderes públicos y estos decidían, discrecionalmente, si se creaban o no tales subvenciones. Ciertamente, una vez establecidas, las subvenciones dejaban normalmente de

28 Señaladamente, por las dudas suscitadas en relación con la necesidad de aprobar bases reguladoras con carácter previo a su concesión. A. R. Rodríguez Castaño (2007), «Las bases reguladoras en las subvenciones de concesión directa a que se refiere el artículo 22.2 c) de la Ley General de Subvenciones en las Corporaciones Locales», en Consultor de los ayuntamientos y de los juzgados, 14 (págs. 2372-2375). 
ser discrecionales y su concesión pasaba a ser reglada, pero ello no implicaba necesariamente que se siguiera un procedimiento de concurrencia competiti$\mathrm{va}^{29}$. Junto a ello, incluso cuando era la Administración quien tomaba la iniciativa de crear las subvenciones, nada le impedía concederlas directamente, sin necesidad de tramitar procedimiento de concurrencia competitiva alguno. La LGS suprimió la posibilidad de que la Administración, por sí misma, pudiera decidir conceder directamente las subvenciones, salvo justamente cuando concurrieran las circunstancias recogidas en el art. 22.2.c LGS. De ahí que, de alguna forma, las «subvenciones excepcionales» reguladas en el art. 22.2.c LGS se hayan convertido en el único reducto de esas antiguas potestades.

El supuesto de hecho recogido en el art. 22.2.c LGS no es un dechado de claridad ni de precisión, tal y como ya señaló la primera doctrina que se encargó de su análisis ${ }^{30}$. En consecuencia, el precepto es susceptible de interpretaciones restrictivas, fundamentalmente propuestas por la doctrina, pero también de interpretaciones muy amplias, que han sido claramente favorecidas por las administraciones públicas encargadas de su aplicación.

Una interpretación muy restrictiva permitiría, en primer lugar, exigir que la situación objeto de subvención fuera una situación verdaderamente excepcional, extremadamente peculiar, singular, única o al menos rarísima en su especie, y que a través de ella se satisficieran intereses generales, lo que justificaría que las administraciones públicas quisieran apoyarla económicamente. Esa singularidad, que debería someterse a un «test de excepcionalidad $»^{31}$, haría absurdo poner en marcha un procedimiento en concurrencia competitiva, dado que desde el principio se conocería al único posible beneficiario. En realidad, su misma excepcionalidad justificaría sobradamente que estas subvenciones se configuraran como subvenciones nominativas en los presupuestos de la Administración correspondiente. En efecto, las situaciones de este tipo podrían identificarse con alguno de esos hechos o acontecimientos singulares (unos juegos olímpicos, una efeméride nacional, una exposición universal, etc.) que también justificarían, como ya indicamos, la previsión de subvenciones nominativas en los presupuestos generales ${ }^{32}$. De hecho, atendiendo precisamente a la relevancia y la magnitud exigibles para considerar verdaderamente

29 Véase, nuevamente, G. Fernández Farreres (1983: 650 y ss.).

30 Especialmente crítico, J. C. Laguna de Paz (2005: 350).

31 Corresponde esta ingeniosa construcción a L. S. Giraldes Rodríguez (2015), «Análisis de la concesión excepcional de subvenciones por razones de interés público, social, económico y diversas. El test de singularidad de la medida», en Revista CEFLegal CEF 174 (págs. 107-111).

32 Véase, por ejemplo, la subvención de 20000000 de euros concedida mediante Real Decreto 1747/2010, de 23 de diciembre, por el que se regula la concesión de una 
excepcionales a estos acontecimientos, lo razonable sería, justamente, que se previera la concesión directa de subvenciones nominativas en los presupuestos generales, de acuerdo con en el art. 22.2.a LGS.

La literalidad del art. 22.2.c LGS no permite acoger fácilmente esta interpretación y exigir, en consecuencia, un grado de excepcionalidad tan intenso. No obstante, en caso de que una situación así se diera, es indudable que tendría cabida en este precepto ${ }^{33}$.

Algo menos restrictiva, y más acorde con la letra y el espíritu del art. 22.2.c LGS, resulta la interpretación que considera que este precepto exige la concurrencia de dos requisitos cumulativos para que la Administración pueda prever la concesión directa de subvenciones. Por un lado, «que se acrediten razones de interés público, social, económico o humanitario». Por otro lado, que estas razones «u otras debidamente justificadas [...] dificulten [la] convocatoria pública [y el procedimiento de concesión en concurrencia competitiva]». De este modo, la Administración estaría obligada a identificar y justificar debidamente la concurrencia de ambos requisitos ${ }^{34}$, lo que habría de tener lugar en el momento de aprobar las bases reguladores de las subvenciones en las que establezca su concesión directa.

Esta interpretación del precepto constituye una interpretación casi literal: las razones de interés público, social, económico, humanitario o de otro tipo que se justifiquen debidamente deben «dificultar» la convocatoria pública de la ayuda, según exige expresamente el art 22.2.c LGS. Esta es también la interpretación del precepto que parece desprenderse de la exposición de motivos $\$ .3$ LGS. $\mathrm{Y}$, seguramente, no puede ser de otra forma, pues la interpretación contraria, que entiende suficiente la concurrencia alternativa de cualquiera de los dos requisitos para que la Administración pueda optar por la concesión directa de la subvención, conduce al absurdo. En efecto, en toda subvención, por definición,

subvención directa al Cabildo Insular de Gran Canaria para la construcción del Palacio de Deportes de Gran Canaria con motivo de la celebración del Mundobasket 2014.

De hecho, algunas leyes autonómicas lo han previsto como una causa distinta a la del art. 22.2.c LGS, aunque, en rigor, debe entenderse incluida dentro de ella como una simple modalidad más. Es el caso del art. 22.3.c.2º de la Ley 10/2006, de 17 de julio, de Subvenciones de Cantabria, que dispone que: «También se podrán otorgar de forma directa las subvenciones cuando las características especiales de la persona beneficiaria o de la actividad subvencionada excluyan la posibilidad de acceso a cualquier otro interesado, haciendo inexistente la concurrencia competitiva». En parecidos términos se expresa el art. 32.1.a de la Ley 6/2011, de 23 de marzo, de Subvenciones de Extremadura, si bien limitando la concesión a subvenciones cuya cuantía sea inferior a 60000 euros y cuando se otorguen a entidades públicas o privadas sin fines de lucro.

34 J. C. Laguna de Paz (2005: 350). 
siempre concurrirá un «interés público, social, económico o humanitario» pues, de lo contrario, no sería posible ni establecerla ni concederla (art. 2.1.c LGS) ${ }^{35}$. Lo realmente relevante no es que concurran tales intereses, que siempre estarán presentes, sino que hagan aconsejable la concesión directa de la subvención por la dificultad o la inconveniencia de realizar una concurrencia competitiva ${ }^{36}$.

No ha sido este, sin embargo, el entendimiento del precepto que ha triunfado en la práctica, sino una interpretación mucho más amplia. La Administración no ha considerado necesario justificar la dificultad de la convocatoria pública para poder acudir al procedimiento de concesión directa. Al menos, no en todos los casos.

Es cierto que, cuando la dificultad o la inconveniencia de acudir al procedimiento de concurrencia competitiva realmente existen, sí se deja constancia de ellas ${ }^{37}$. Pero, en caso de que no concurran, la Administración considera suficiente señalar la existencia de cualquier «interés público, social, económico o humanitario» que se vea satisfecho con la entrega de la subvención para poder justificar su concesión directa ${ }^{38}$. $\mathrm{O}$, en el mejor de los casos, señala que la concesión directa puede ser más conveniente que la concesión en concurrencia competitiva. Conveniencia que habitualmente va ligada a la mayor celeridad y simplicidad del procedimiento de concesión directa frente al procedimiento de concurrencia competitiva, aunque no se justifique por qué es necesaria tanta celeridad en el caso concreto ni por qué es conveniente renunciar en su nombre a los principios de concurrencia o eficiencia en la asignación y utilización de los recursos públicos ${ }^{39}$.

35 Un análisis especialmente detenido de las implicaciones de este requisito en Bueno Armijo (2013: 81 y ss.).

36 En el mismo sentido, J. Pascual García (2016: 278).

37 Especialmente ilustrativo resulta, en este sentido, el Real Decreto 185/2016, de 6 de mayo, por el que se regula la concesión directa de una subvención a la Ciudad de Melilla por los gastos de emergencia realizados con motivo del terremoto acaecido el día 25 de enero de 2016. Tratándose de una situación única en la que no existían otros posibles beneficiarios, al ser Melilla la única ciudad española afectada, no habría tenido sentido tramitar una concurrencia competitiva para dar cabida a las imposibles solicitudes de otras ciudades.

38 Solo por citar alguno de los ejemplos más recientes, la única justificación que ofrece el preámbulo del Real Decreto 704/2017, de 7 de julio, por el que se establecen las bases reguladoras para la concesión directa de las subvenciones estatales para la renovación del parque nacional de maquinaria agraria, es que «Se prevé la concesión directa de estas ayudas, dado que, de acuerdo con el artículo 22.2.c) de la Ley 38/2003, de 17 de noviembre, General de Subvenciones, concurren razones de interés social y económico».

39 Por ejemplo, el Real Decreto 70/2017, de 10 de febrero, por el que se establece la concesión de una ayuda excepcional de adaptación al sector productor vacuno de 
El resultado es que la Administración ha acabado recuperando la potestad de decidir, discrecionalmente, cuándo las subvenciones que establezca se concederán en concurrencia competitiva y cuándo se concederán directamente. Justamente lo que el art. 22.2 LGS trataba de erradicar.

En muchos de estos casos, el problema de fondo es el deseo de la Administración de que todo aquel que se encuentre en una determinada situación o reúna ciertos requisitos pueda recibir la subvención, sin necesidad de comparar su situación con la de otros solicitantes ${ }^{40}$. Pero esta posibilidad, como explicamos en la introducción de este trabajo, es justamente la que el legislador básico, consciente y deliberadamente, ha desterrado, al imponer que el procedimiento de concesión en concurrencia competitiva sea el procedimiento ordinario de otorgamiento de subvenciones. En otros muchos casos, además, lo que la Administración persigue es, lisa y llanamente, recuperar algunas de las potestades discrecionales de intervención que la LGS le arrebató y que desea recuperar por cualquier medio. Timeo Danaos et dona ferentes... ${ }^{41}$.

leche, señala en su preámbulo que: «El sector lácteo atraviesa una difícil situación, consecuencia de la confluencia de una serie de factores que han dado lugar a un importante desequilibrio del mercado y una prolongada caída de los precios pagados a los productores. [...] Dada la urgencia de adoptar medidas que afronten la situación descrita y el principio de simplificación administrativa y reducción de cargas [...] se prevé la concesión directa de estas ayudas, dado que, de acuerdo con el artículo 22.2.c) de la Ley 38/2003, de 17 de noviembre, General de Subvenciones, concurren razones de interés social y económico, por los motivos ya expuestos». En realidad, la situación de crisis del sector lechero y la sucesión de medidas para intentar paliarla, lejos de ser una novedad insólita, se arrastran desde hace años, por lo que es difícil entender la urgencia de la concesión de estas precisas ayudas.

Véase, por ejemplo, el ya indicado Real Decreto 617/2017, de 16 de junio, por el que se regula la concesión directa de ayudas para la adquisición de vehículos de energías alternativas, y para la implantación de puntos de recarga de vehículos eléctricos en 2017 (Plan MOVEA 2017).

41 Así, no es fácil entender por qué la Administración General del Estado decidió conceder directamente una importante subvención (2000 000 euros) para que se construyera un centro de servicios sociales en un municipio concreto, lo que era responsabilidad de la comunidad autónoma correspondiente, sin dar la posibilidad a otras comunidades autónomas de que solicitasen idénticas ayudas para el mismo fin para otros municipios, aun cuando pudieran necesitarlo más. Véase, Real Decreto 1715/2011, de 18 de noviembre, por el que se regula la concesión directa de una subvención a la Junta de Andalucía para financiar la construcción de un centro de servicios sociales de atención especializada en Jaén. Como simple curiosidad, puede señalarse la casualidad de que la subvención se aprobara dos días antes de la celebración de unas elecciones generales ( 20 de noviembre de 2011) y de que el secretario de Estado de Cooperación Territorial concurriera a tales 
Obedezca al motivo que obedezca, lo relevante es que esta interpretación amplia del art. 22.2.c LGS propuesta por la Administración ha sido aceptada por la jurisprudencia. Así, los tribunales no consideran necesario exigir a la Administración que justifique la dificultad o inconveniencia de acudir al procedimiento de concesión en concurrencia competitiva, siendo suficiente con que acredite que la subvención satisfará un interés general ${ }^{42}$. A lo sumo, en alguna ocasión han exigido que la Administración motive por qué estima más conveniente acudir a la concesión directa, lo que no es lo mismo que exigir la acreditación de la dificultad o la inconveniencia de la concurrencia competitiva, que es lo que la literalidad del art. 22.2.c LGS impone. De este modo, se ha admitido, por ejemplo, que la Administración pueda acudir a la concesión directa simplemente por considerarlo un procedimiento más ágil y eficaz que la concurrencia competitiva y por permitir una rápida percepción de las ayudas por parte de los beneficiarios ${ }^{43}$; razonamiento que, por sí solo, permitiría sustituir todos los

elecciones, justamente, por la circunscripción electoral de Jaén. Tampoco resulta nada fácil de entender la subvención de 7000000 de euros concedida directamente por la Administración General del Estado al proyecto de «innovación y ciencia» [sic] Basque Culinary Center, promovido por una Universidad privada (Mondragon Unibertsitatea), especialmente cuando el acceso a este tipo de financiación para las Universidades públicas se hace a través de complejísimos y pesadísimos procedimientos en concurrencia competitiva. Véase, Real Decreto 1640/2009, de 30 de octubre, por el que se establecen las normas reguladoras de la subvención de concesión directa a la entidad Basque Culinary Center Fundazioa para la puesta en marcha del proyecto Basque Culinary Center. En relación con esta precisa subvención, ya mostró su estupor Fernández Farreres (2012: 22).

42 Entre los más claros exponentes de esta jurisprudencia, la STS de 14 de noviembre de 2011 (recurso 1/2008, ponente: Espín Templado), aceptó que en el art. 22.2.c LGS existen dos supuestos distintos que admiten la concesión directa: «El artículo 22.2 de la Ley de Subvenciones enumera los casos en los que es posible otorgar concesiones de forma directa, y en el apartado c) contempla "con carácter excepcional" un doble supuesto, el de las "subvenciones en que se acrediten razones de interés público, social, económico o humanitario" y el de las subvenciones en que se acrediten "otras [razones] debidamente justificadas que dificulten su convocatoria pública". El precepto reglamentario citado [se refiere al art. 67 RGS] desarrolla esta previsión requiriendo una memoria del órgano gestor de las subvenciones competente por razón de la materia que justifique la concurrencia de alguno de los dos citados supuestos citados, la de las razones de interés público, etc., o de las otras que justifican la dificultad de su conveniencia pública» (cursivas añadidas).

43 STJS de Madrid de 7 de noviembre de 2016 (recurso 271/2015, ponente: Díaz Fernández), en relación con la concesión de incentivos a la contratación por cuenta ajena de trabajadores desempleados por importe de 10000 euros. 
procedimientos de concesión en concurrencia competitiva por procedimientos de concesión directa y que debe ser tajantemente rechazado ${ }^{44}$.

Esta jurisprudencia resulta criticable por las razones ya expuestas, pero no resulta tan grave como la consagración que esta interpretación amplia ha conocido en la legislación sobre subvenciones de alguna comunidad autónoma. Así el art. 14.5.c de la Ley 5/2015, de 25 de marzo, de Subvenciones de Aragón, señala abiertamente que podrán concederse de forma directa aquellas subvenciones en las que, simplemente, «se acrediten razones de interés público, social, económico o humanitario». En la medida en que, por definición, y como hemos repetido, es posible acreditar razones de interés público en absolutamente todas las subvenciones, el precepto trascrito implica que siempre resultará posible para la Administración aragonesa otorgar subvenciones mediante concesión directa. Y aun más generoso (e inconstitucional) se muestra el art. 120.1.2 ${ }^{\circ}$ Decreto Legislativo $1 / 2010$, de 2 de marzo, por el que se aprueba el texto refundido de la Ley General de la Hacienda Pública de la Junta de Andalucía, el cual admite que: «A solicitud de la persona o entidad interesada, podrán concederse subvenciones en atención a la mera concurrencia de una determinada situación en el perceptor, sin que sea necesario establecer, en tales casos, la comparación de las solicitudes ni la prelación entre las mismas». Esto es, el sistema de «subvenciones rogadas» expresa, voluntaria y deliberadamente desterrado por la LGS, sin necesidad ni tan siquiera de acreditar la concurrencia de intereses generales.

Los abusos en la utilización de esta causa de concesión de subvenciones no han pasado, sin embargo, inadvertidos, hasta el punto de que ya han circulado trabajos preparatorios de leyes básicas que proponen su eliminación.

En la exposición de motivos $\$ .2$ del anteproyecto de ley de modificación de la Ley General de Subvenciones que hizo circular el Gobierno durante los primeros meses de 2014, se indicaba, expresamente, que:

[...] se elimina la posibilidad de tramitar la concesión de subvenciones de forma directa en base a motivos de interés público, social, económico o humanitario,

44 No debe perderse de vista que la rapidez en la tramitación de las subvenciones, como en cualquier otro procedimiento, depende sobre todo de la Administración. El legítimo interés en resolver un procedimiento en el menor plazo no debe satisfacerse al coste de eliminar las garantías de eficiencia en el gasto público y de igualdad entre todos los ciudadanos. Por el contrario, el ordenamiento prevé muchos otros mecanismos para ello, aplicables a cualquier procedimiento administrativo (tramitación de urgencia, art. 33 LPAC) o, específicamente, al ámbito de las subvenciones, como la convocatoria abierta (art. 59 RGS; art. 28 de la Ley 6/2011, de 23 de marzo, de Subvenciones de Extremadura). 
tal y como se recogían en la letra 22.2.c) de la ley, pues, pese a su carácter excepcional, se ha advertido que, con el paso del tiempo, se estaba empleado de forma abusiva, extralimitándose respecto a los márgenes previstos en la ley. Asimismo, el carácter excepcional de la concesión de subvenciones de forma directa determina que deba ser regulada por una norma de rango legal, posibilidad que ya aparece contemplada en la letra 22.2.b) de la propia ley, que, en consecuencia, se mantiene ${ }^{45}$.

El anteproyecto, finalmente, no llegaría a presentarse a las Cortes y únicamente algunos de sus artículos acabaron incorporándose a la Ley 15/2014, de 16 de septiembre, de racionalización del sector público y otras medidas de reforma administrativa, aunque sin afectar al art. 22 LGS ni al procedimiento de concesión directa de subvenciones. Se trata de una buena noticia, porque la eliminación completa del art. 22.2.c LGS seguramente habría sido un error. Reservar al legislador en exclusiva la potestad de señalar los supuestos en que cabe la concesión directa de subvenciones introduciría una rigidez excesiva e inconveniente. Es razonable que la Administración cuente también con la potestad de apreciar cuándo el procedimiento de concesión en concurrencia competitiva puede resultar contrario al interés general y cuándo, por tanto, resulta más oportuno acudir a la concesión directa. Sin embargo, dicha potestad administrativa necesita una regulación adecuada, algo más restrictiva que la que actualmente permite extraer el art. 22.2.c LGS. De lo contrario, todo el esfuerzo del legislador por configurar la concurrencia competitiva como el procedimiento «ordinario» de concesión de subvenciones acaba siendo en vano.

\section{SUPUESTOS DE CONCESIÓN DIRECTA DE SUBVENCIONES AL MARGEN DEL ARTíCULO 22.2 DE LA LEY GENERAL DE SUBVENCIONES}

Pese a la rotundidad del art. 22.2 LGS y, muy especialmente, del art. 55.2 RGS («Las subvenciones solo podrán concederse en forma directa en los casos previstos en el artículo 22.2 de la Ley»), las administraciones públicas españolas conceden subvenciones directamente, sin necesidad de acudir al procedimiento de concurrencia competitiva, en más supuestos de los previstos en el indicado art. 22.2 LGS.

45 Esta propuesta traía causa del llamado «Informe CORA - Comisión para la Reforma de las administraciones públicas», presentado al Consejo de Ministros por la vicepresidenta del Gobierno y ministra de la Presidencia y por el ministro de Hacienda y Administraciones Públicas el 21 de junio de 2013. 
En algunos casos, la concesión directa obedece a una imposición del derecho de la Unión Europea sobre las administraciones nacionales. En otros, la concesión directa encuentra amparo en la propia normativa básica del Estado, que ha completado lo dispuesto en el art. 22.2 LGS. No obstante, han sido los legisladores autonómicos los que en mayor medida han ampliado los supuestos de concesión directa de subvenciones, yendo mucho más lejos de lo que el legislador básico admitiría. No se trata de una situación plenamente desconocida, pero lo cierto es que la doctrina ha prestado poca atención a estas innovaciones de los legisladores autonómicos y a su más que dudosa constitucionalidad ${ }^{46}$.

\section{LA CONCESIÓN DIRECTA DE SUBVENCIONES FINANCIADAS CON CARGO A FONDOS DE LA UNIÓN EUROPEA}

Los procedimientos de concesión de subvenciones regulados en los arts. 22 y ss. LGS solo tienen carácter supletorio respecto de la normativa reguladora de las subvenciones financiadas con cargo a fondos de la Unión Europea (art. 6.2 LGS). En efecto, estas subvenciones se rigen, en primer lugar, por las normas de la Unión aplicables en cada caso y, solo en la medida en que sea necesario, por la normativa nacional de desarrollo o transposición de las mismas.

De este modo, cuando las administraciones nacionales actúen como Administración de la Unión y concedan subvenciones en ejecución de las distintas políticas comunes, deberán aplicar, en primer lugar, el derecho de la Unión, siendo perfectamente posible que este haya establecido que tales subvenciones deban otorgarse en régimen de concesión directa. Así ocurre, justamente, con la mayor parte de las ayudas concedidas en el marco de la Política Agrícola Común bajo forma de "pagos directos».

Únicamente cuando el derecho de la Unión no se pronuncie sobre el modo en que deban ser concedidas las subvenciones financiadas con cargo a sus propios fondos, resultará de aplicación la LGS. En estos casos será

46 Por excepción, y con especial acierto, advirtieron tempranamente de esta situación M. Carlón Ruiz y F. González Botija (2007), «La ordenación autonómica de subvenciones», en G. Fernández Farreres (dir.), El régimen jurídico de las subvenciones. Derecho español y comunitario, Madrid: CGPJ (págs. 109-113), si bien refiriéndose a una situación normativa que en ese momento era apenas incipiente y que se ha visto ampliamente desbordada desde entonces, a raíz de la aprobación de nuevas leyes reguladoras de las subvenciones en muchas CC.AA. Para el caso específico de la Comunidad Autónoma Valenciana, Collado Beneyto (2009: 510-511). Con menor detalle, y en relación con la normativa de subvenciones de la Comunidad de Madrid anterior a la LGS, A. Frías López (2005), «Procedimientos de concesión de subvenciones tras la Ley 38/2003, de 17 de noviembre, General de Subvenciones», en Revista Jurídica de la Comunidad de Madrid, 22 (págs. 245-284). 
nuevamente obligatorio para las administraciones españolas encargadas de su otorgamiento acudir al procedimiento de concesión en concurrencia competitiva, salvo en los casos autorizados en el art. 22.2 LGS ${ }^{47}$. Todo ello constituye, sencillamente, una aplicación a este ámbito del principio de autonomía para la ejecución del derecho de la Unión del que gozan los Estados miembros, que deberá ser adecuadamente matizado, cuando sea necesario, por los principios de eficacia y equivalencia ${ }^{48}$.

\section{LA CONCESIÓN DIRECTA DE SUBVENCIONES EN MATERIA DE COOPERACIÓN INTERNACIONAL}

La Disposición adicional decimoctava LGS habilita al Gobierno a establecer un régimen especial de concesión de subvenciones en el ámbito de la cooperación internacional ${ }^{49}$ :

47 En relación con la determinación del régimen jurídico aplicable a las subvenciones gestionadas por la Administración española en ejecución del derecho de la Unión, A. Bueno Armijo (2011), El reintegro de subvenciones de la Unión Europea, Sevilla: Instituto Andaluz de Administración Pública (págs. 131-146).

Por ejemplo, el «Programa Operativo de Crecimiento Sostenible para el periodo 2014-2020", aprobado por la Comisión Europea y financiado con cargo al fondo FEDER, no incluye indicaciones acerca del modo en que deban concederse las ayudas sufragadas con cargo a él por parte de las administraciones nacionales. Para su ejecución, el Gobierno aprobó el Real Decreto 616/2017, de 16 de junio, por el que se regula la concesión directa de subvenciones a proyectos singulares de entidades locales que favorezcan el paso a una economía baja en carbono en el marco del programa operativo FEDER de crecimiento sostenible 2014-2020. El Gobierno estimó justificado acudir a la vía del art. 22.2.c LGS por la necesidad de tramitar las ayudas rápidamente, a fin de ejecutar toda la financiación recibida de la Unión Europea en plazo. Pero, justamente, el hecho de que considerara necesario justificar por qué se acudía a la concesión directa y el esfuerzo en motivar por qué concurría el supuesto descrito en el art. 22.2.c LGS implican que asumía, como punto de partida, que también estas subvenciones deben concederse de acuerdo con el procedimiento de concurrencia competitiva.

49 Ya la disposición final segunda de la Ley 31/1991, de 30 de diciembre, de Presupuestos Generales del Estado para 1992, encomendó al Gobierno la aprobación, mediante Real Decreto, de las normas especiales reguladoras de las ayudas y subvenciones de cooperación internacional que fueran desarrollo de su política exterior, autorizando expresamente la posibilidad de excepcionar los principios de publicidad y concurrencia en la concesión de subvenciones, contenidos en aquel momento en el texto refundido de la Ley General Presupuestaria. 
1. El Gobierno aprobará por real decreto, a propuesta conjunta de los Ministerios de Asuntos Exteriores y de Hacienda, las normas especiales reguladoras de las subvenciones de cooperación internacional.

2. Dicha regulación se adecuará con carácter general a lo establecido en esta ley, salvo que deban exceptuarse los principios de publicidad o concurrencia u otros aspectos del régimen de control, reintegros o sanciones, en la medida en que las subvenciones sean desarrollo de la politica exterior del Gobierno y resulten incompatibles con la naturaleza o los destinatarios de las mismas.

En desarrollo de esta previsión, se dictó el Real Decreto 794/2010, de 16 de junio, por el que se regulan las subvenciones y ayudas en el ámbito de la cooperación internacional. Esta norma distingue varios tipos de subvenciones y ayudas, de las cuales, solo las recogidas en su título I bajo el nombre de «subvenciones y ayudas de cooperación internacional concedidas en desarrollo de la política exterior del gobierno» (arts. 5-21) están amparadas por la disposición adicional decimoctava LGS. Dentro de ellas, tampoco todas las medidas previstas adoptan la forma de verdaderas subvenciones, en el sentido del art. 2 LGS. Así, no parecen entrar en esta categoría, por ejemplo, ninguno de los instrumentos definidos en el art. 2 Real Decreto 794/2010 y a los que específicamente se refiere el art. 5.2 RD 794/2010 (apoyo presupuestario general, apoyo presupuestario sectorial, fondo global, fondo común, cooperación delegada o cooperación triangular).

Sin embargo, sí pueden concederse verdaderas subvenciones a programas, proyectos o actividades de cooperación internacional realizados no solo por terceros Estados y organizaciones internacionales, sino también por todo tipo de personas físicas y jurídicas, públicas y privadas, tanto nacionales como extranjeras. Es a estos últimos supuestos a los que, propiamente, se refiere la excepción contenida en la disposición adicional decimoctava LGS.

Lo determinante de ellas es que parecen configurarse como manifestaciones paradigmáticas de «actos políticos» adoptados por el Gobierno. De hecho, es a esto a lo que parece referirse el artículo cuando señala como justificación de la excepcionalidad de su régimen «que las subvenciones sean desarrollo de la política exterior del Gobierno». En efecto, estas ayudas permitirían, por ejemplo, dar cumplimiento a compromisos internacionales asumidos por el Gobierno ${ }^{50}$.

Son bien conocidos los debates acerca de la pervivencia del acto político en nuestro ordenamiento jurídico y las autorizadas opiniones que la han

50 I. M. Arteagabeitia González (2011), «Las subvenciones de cooperación internacional», en M. Garcés Sanagustín y A. Palomar Olmeda (coords.), Derecho de las subvenciones y ayudas públicas, Cizur Menor: Aranzadi-Thomson Reuters (págs. 708 y 736). 
negado. Pero lo cierto es que nuestro Tribunal Constitucional parece asumir su existencia ${ }^{51}$ y que, tradicionalmente, se ha considerado que las relaciones internacionales o, por expresarlo en los términos del art. $97 \mathrm{CE}$, la dirección de la política exterior, constituye uno de los ámbitos en los que cabe dictarlos (negociación y firma de tratados internacionales, establecimiento o ruptura de relaciones diplomáticas, envío de misiones humanitarias, etc.). En este contexto, también la concesión de subvenciones que afectan directamente a terceros Estados puede constituir una forma de desarrollar o ejecutar la política exterior de España, dando lugar a situaciones en las que seguramente carece de sentido aplicar las normas propias de la concesión en concurrencia competitiva. Situaciones que se entienden especialmente bien cuando la concesión de subvenciones se utiliza, como ha ocurrido en ocasiones, para afrontar crisis internacionales que han afectado a España ${ }^{52}$.

Todo lo anterior justifica la previsión contenida en el art. 10.5 del Real Decreto 794/2010, de conformidad con el cual: «Las subvenciones o ayudas se concederán individualizadamente de oficio o a instancia de los interesados, mediante la apreciación discrecional de las circunstancias que concurran en cada caso». Es interesante destacar que el hecho de que la norma indique, expresamente, que la concesión se realiza «individualizadamente» ratifica su carácter de subvenciones otorgadas en concesión directa, en tanto que la resolución individualizada impide, por definición, la comparación entre solicitudes.

Y una justificación similar podría encontrarse al art. 10.6 Real Decreto $74 / 2010$, que establece que estas subvenciones «se conceden bajo reserva de revocación, además de por las causas previstas en el artículo 21 de este real decreto, cuando, previa declaración por Acuerdo de Consejo de Ministros, hubieran variado las circunstancias o razones que aconsejaron su otorgamiento, y

51 Véase la reciente STC 83/2016, de 28 de abril, en relación con el acuerdo del Consejo de Ministros de 14 de diciembre de 2010 por el que se solicitaba al Congreso de los Diputados la autorización para prorrogar el estado de alarma declarado para la normalización del servicio público esencial de transporte aéreo.

52 Así, entre las medidas adoptadas por el Gobierno para enfrentarse a la llamada «crisis de los cayucos», que tuvo lugar entre 2005 y 2006 y que se caracterizó por un espectacular aumento de arribadas a las islas Canarias de embarcaciones con inmigrantes irregulares procedentes de la costa occidental africana, se aprobaron, por un valor conjunto de algo más de 11 millones de euros, el Real Decreto 845/2006, de 7 julio, por el que se regula la concesión de una subvención extraordinaria al Reino de Marruecos para la mejora del control de sus fronteras y lucha contra la emigración ilegal, y el Real Decreto 187/2007, de 9 febrero, por el que se regula la concesión de una subvención extraordinaria a la República Islámica de Mauritania para la mejora del control de sus fronteras y lucha contra la emigración ilegal. 
sin perjuicio de resarcimiento cuando corresponda». Los actos administrativos favorables, como serán por lo general los actos de concesión de subvenciones, no son libremente revocables en derecho español, según se afirma tradicionalmente, merced al llamado "principio de intangibilidad». A tal efecto, es irrelevante que su otorgamiento se produzca en el ejercicio de una potestad reglada o discrecional. Por ello, es dudoso que una norma de mero rango reglamentario, como este Real Decreto, pueda establecer, por sí misma, esta «reserva de revocación». Ahora bien, la situación cambia por completo si entendemos que la concesión de estas subvenciones no es el resultado del ejercicio de una potestad discrecional, sino un verdadero acto político, entendido, por utilizar la expresión clásica contenida en la exposición de motivos de la Ley de la Jurisdicción Contencioso-Administrativa de 1956, \$.II.4, no como «una especie del género de los actos administrativos discrecionales, caracterizada por un grado máximo de la discrecionalidad, sino [como] actos esencialmente distintos por ser una la función administrativa y otra la función política, confiada únicamente a los supremos órganos estatales».

Esta interpretación sería coherente con el alcance de la habilitación concedida al Gobierno para establecer un régimen especial para las subvenciones en materia de cooperación internacional, la cual cubriría únicamente aquellas subvenciones que "sean desarrollo de la política exterior del Gobierno» y permitiría solamente excluir «los principios de publicidad o concurrencia u otros aspectos del régimen de control, reintegros o sanciones, en la medida en que $[. .$.$] resulten incompatibles con la naturaleza o los destinatarios» de las$ subvenciones (DA18 $\left.{ }^{\mathrm{a}} \mathrm{LGS}\right)$. Es decir, como regla general, también las subvenciones concedidas en materia de cooperación internacional se regirán plenamente por la LGS y solo excepcionalmente gozarán de un régimen propio y necesario por encontrarnos ante actuaciones que constituyen, en puridad, actos políticos del Gobierno. Fuera de estos casos, el otorgamiento de subvenciones, como en cualquier otro ámbito, deberá realizarse de acuerdo con el procedimiento de concurrencia competitiva, a menos que concurra alguno de los supuestos del art. 22.2 LGS, ya analizados ${ }^{53}$.

Evidentemente, las excepciones a la regla general autorizadas por la disposición adicional decimoctava LGS solo podrán resultar de aplicación al Es-

53 Así lo reconoce expresamente, por ejemplo, la disposición adicional segunda de la Ley 9/2007, de 13 de junio de Subvenciones de Galicia, que señala que: «Las subvenciones en materia de cooperación para el desarrollo reguladas en la Ley 3/2003, de 19 de junio, se someterán en su concesión a los principios de publicidad y concurrencia, salvo que proceda la aplicación del régimen previsto en el artículo 19.4 de la presente ley [que reproduce el art. 22.2 LGS]». En sentido parecido, arts. 32.1.c, 32.2 y disposición adicional sexta de la Ley 6/2011, de 23 de marzo, de Subvenciones de Extremadura. 
tado, único que, propiamente, puede desarrollar una «política exterior» que justifique un régimen de concesión de subvenciones distinto al previsto con carácter general en la LGS ${ }^{54}$. Sin embargo, algunas comunidades autónomas han incluido en sus respectivas leyes de subvenciones previsiones prácticamente idénticas a la disposición adicional decimoctava LGS, habilitando a sus Consejos de Gobierno para aprobar normas que exceptúen el régimen ordinario de concesión de subvenciones públicas en concurrencia competitiva cuando se concedan en el marco de sus políticas de cooperación exterior.

Paradigmático es el caso del art. 5 del Decreto Legislativo 2/2005, de 28 de diciembre, por el que se aprueba el texto refundido de la Ley Balear de Subvenciones, el cual reproduce, casi literalmente, la disposición adicional decimoctava LGS. También la disposición adicional octava de la Ley 10/2006, de 17 de julio, de Subvenciones de Cantabria, habilita al Consejo de Gobierno cántabro para aprobar normas especiales reguladoras de las subvenciones de cooperación internacional que podrán exceptuar, entre otros, los principios de publicidad o concurrencia, «en la medida en que las subvenciones sean consecuencia de la política humanitaria y de cooperación al desarrollo del Gobierno y resulten incompatibles con la naturaleza o los destinatarios de las mismas». La propia existencia de una "política humanitaria y de cooperación al desarrollo» del Gobierno de Cantabria suscita dudas, dado que su Estatuto de Autonomía no le atribuye competencia alguna en esta materia. Pero lo que es seguro es que en ningún caso sería título competencial suficiente para excepcionar el carácter básico de los arts. 22.2 LGS y 55 RGS ni, consecuentemente, crear un nuevo supuesto de concesión directa de subvenciones ${ }^{55}$.

$\mathrm{Y}$ con mayor motivo aun deben rechazarse otras previsiones legales autonómicas que admiten la concesión directa de subvenciones en materia de

54 De acuerdo con una constante doctrina constitucional, las comunidades autónomas pueden realizar «actividades con proyección exterior», pero «limitadas a aquellas que no impliquen el ejercicio de un ius contrahendi, no originen obligaciones inmediatas y actuales frente a los poderes públicos extranjeros, no incidan en la política exterior del Estado y no generen responsabilidad de este frente a Estados extranjeros u organizaciones inter o supranacionales» (SSTC 46/2015, FJ 4, y 85/2016, FJ 3).

55 En términos muy parecidos se expresa la disposición adicional tercera de la Ley 5/2015, de 25 de marzo, de Subvenciones de Aragón, que justifica un régimen excepcional para las subvenciones que «sean aplicación de la política de cooperación para el desarrollo del Gobierno». Debe advertirse que, al menos, el art. 71.36 a del Estatuto de Autonomía de Aragón sí atribuye competencia exclusiva en materia de "cooperación para el desarrollo [...] con los países y pueblos más desfavorecidos». No obstante, tampoco en este caso sería título suficiente para excepcionar la regulación básica del Estado en materia de subvenciones. 
cooperación internacional como categoría general, sin ni siquiera vincularlas a una supuesta "política exterior» o de "proyección institucional»"

La concesión directa en todos estos supuestos solo resultará admisible en la medida en que pueda acreditarse, caso por caso, que concurren circunstancias que justifican la dificultad de su convocatoria pública. Es decir, cuando resulte posible reconducirlos al supuesto de concesión directa recogido en el art. 22.2.c LGS. Esta ha sido, al menos de momento, la interpretación que también han acogido los tribunales ${ }^{57}$.

\section{LA CONCESIÓN DIRECTA DE SUBVENCIONES DE FACTO}

Como ya hemos indicado, el art. 55 RGS reitera que el procedimiento ordinario de concesión de subvenciones será el de concurrencia competitiva y que las subvenciones solo podrán concederse en forma directa en los casos previstos en el art. 22.2 LGS. Sin embargo, el art. 55 RGS incorpora también una interesante novedad no prevista en la LGS: en el caso de que, una vez finalizado el plazo de presentación de solicitudes en un procedimiento de concurrencia competitiva, el crédito consignado fuera suficiente para cubrir todas las solicitudes presentadas que reunieran los requisitos establecidos, no será necesario evaluarlas ni establecer un orden de prelación entre ellas. Dicho de otra forma, comprobado que los solicitantes reúnen los requisitos que permiten ser admitidos en el procedimiento, y existiendo crédito suficiente para cubrir todas las solicitudes, se procederá a la concesión directa de las subvenciones a todos ellos ${ }^{58}$.

Se trata de una razonable simplificación del procedimiento administrativo de concesión de subvenciones en concurrencia competitiva, pues, en la medida en que varios trámites se vuelven innecesarios, se puede y se debe

56 Disposición adicional tercera de la Ley Foral 11/2005, de 9 de noviembre, de Subvenciones de Navarra.

57 La STSJ Baleares de 19 de diciembre de 2012 (recurso no 547/2011, ponente: Ortuño Rodríguez) salva justamente una subvención concedida directamente, en virtud del art. 5 del Decreto Legislativo 2/2005, de 28 de diciembre, por el que se aprueba el Texto Refundido de la Ley Balear de Subvenciones, antes señalado, al entender que se incardina dentro del supuesto del art. 22.2.c LGS.

58 Sin perjuicio del carácter básico del art. 55 RGS y de su directa aplicabilidad a todas las administraciones públicas, algunas normas autonómicas también han recogido expresamente esta posibilidad: art. 22.1.3º de la Ley 6/2011, de 23 de marzo, de Subvenciones de Extremadura; art. 19.2 de la Ley 9/2007, de 13 de junio, de Subvenciones de Galicia. 
prescindir de ellos (art. 1.2 LPAC) ${ }^{59}$. A efectos prácticos, esta posibilidad prevista en el art. 55.1.2० RGS supone convertir de hecho un procedimiento de concesión en concurrencia competitiva en un procedimiento de concesión directa. Ahora bien, esta "concesión directa de facto» tiene importantes diferencias con la «concesión directa de iure»:

- Por un lado, el intento de hacer un reparto del modo más eficiente posible (esto es, priorizando a quienes más merecen la subvención de acuerdo con los criterios objetivos fijados en las bases reguladoras) se ve frustrado por una cuestión meramente circunstancial, por unos hechos sobrevenidos, pero no por la voluntad de la Administración;

- Por otro lado, y como consecuencia de lo anterior, la Administración nunca puede conocer con antelación si podrá aplicarse esta forma de concesión o no. Ello implica que, a diferencia de lo que ocurrirá con las demás formas de concesión directa, no podrá resolver en ningún caso individualizadamente las solicitudes que se le presenten a medida que las vaya recibiendo. Es decir, hasta que no haya terminado el plazo de presentación de solicitudes y sepa cuántas solicitudes han sido presentadas y la cuantía pedida, la Administración concedente no tendrá forma de saber si se cumplen los requisitos marcados por el art. 55.1.2 $2^{\circ} \mathrm{RS} \mathrm{ni}$, consecuentemente, si puede proceder a la concesión directa de las subvenciones.

Existe, sin embargo, una forma de crear artificialmente las circunstancias que permiten aplicar el art. 55.1.20 RGS y a la que la Administración podría acudir: configurar en la Ley de Presupuestos el crédito al que se impute una determinada subvención como crédito ampliable. Esta configuración permitiría a la Administración saber, desde el primer momento, que tendrá crédito suficiente para atender a todas las solicitudes que se le presenten. Consecuentemente, nada obstará a que vaya resolviendo individualizadamente sobre cada solicitud a medida que se le van presentando.

No se trata, por lo demás, de una mera posibilidad teórica. El art. 22.2.4 in fine de la Ley 10/2006, de 17 de julio, de Subvenciones de Cantabria, tras regular el procedimiento de concurrencia competitiva dispone, expresamente,

59 El art. 22 de la Ley 9/2007, de 13 de junio, de Subvenciones de Galicia, configura expresamente este supuesto como un "procedimiento abreviado" eliminando la intervención del órgano evaluador que impone para los procedimientos de concesión en concurrencia competitiva, con carácter general, el art. 22.1 LGS, y estableciendo que la propuesta de concesión se formulará al órgano concedente directamente por el órgano instructor. 
que «cuando la Ley de Presupuestos configure el crédito al que se imputen como ampliable $[\ldots]$ se podrán tramitar por el procedimiento de concesión directa».

El efecto que se consigue es lo que podríamos llamar una «concesión directa de facto inducida», cuya compatibilidad con la normativa básica debe reputarse, en el mejor de los casos, muy dudosa.

\section{LA CONCESIÓN DIRECTA DE SUBVENCIONES A TRAVÉS DE CONVENIOS DE COLABORACIÓN}

Los convenios de colaboración firmados entre administraciones o entre administraciones y sujetos privados han podido constituir, tradicionalmente, un verdadero agujero negro del régimen jurídico de las subvenciones públicas. No obstante, para entender adecuadamente los términos del problema debe distinguirse, en primer lugar, entre convenios que simplemente ponen fin a un procedimiento administrativo de concesión de subvenciones y convenios que crean por sí mismos la subvención. Son estos segundos los que nos interesan ahora y los que, adelantamos, deben rechazarse.

En relación con los primeros, no hay mucho que objetar. Tanto el art. 28 LGS como los arts. 65-67 RGS reconocen que los convenios pueden ser un instrumento idóneo para poner fin al procedimiento de concesión directa de subvenciones o «canalizar» su otorgamiento ${ }^{60}$. En el caso de las subvenciones previstas nominativamente en los Presupuestos Generales del Estado o en los de las corporaciones locales (art. 22.2.a LGS), los convenios serán, incluso, «el instrumento habitual» para formalizar su concesión (art. 28.1.2 LGS). Pero su uso es igualmente admisible para la concesión directa de subvenciones previstas en norma con rango de ley (art. 22.2.b LGS) o para la concesión directa de subvenciones excepcionales (art. 22.2.c LGS). En ninguno de estos casos, volvemos a insistir, el convenio crea la subvención, sino que se limita simplemente a formalizar su otorgamiento.

Ahora bien, junto a este tipo de convenios, las administraciones han utilizado también los convenios de colaboración para establecer y conceder directamente subvenciones, al margen de los supuestos previstos en el art. 22.2 LGS, como una vía alternativa más de concesión directa, sin publicidad y sin concurrencia. En estos casos, la Administración identifica una forma de «mejorar la eficiencia de la gestión pública, facilitar la utilización conjunta de medios

60 Art. 28.1.1 LGS: «La resolución de concesión y, en su caso, los convenios a través de los cuales se canalicen estas subvenciones [otorgadas en concesión directa] establecerán las condiciones y compromisos aplicables de conformidad con lo dispuesto en esta ley». 
y servicios públicos [o de] contribuir a la realización de actividades de utilidad pública» (art. 48.3 LRJSP), y decide suscribir un acuerdo con efectos jurídicos con otra Administración pública o con un sujeto privado, comprometiéndose a entregarle una cantidad de dinero para lograr ese objetivo conjunto. Todo ello, al margen de que concurra o no alguno de los supuestos del art. 22.2 LGS. Y aun cuando tales aportaciones constituyen auténticas subvenciones ${ }^{61}$.

Se trata de una práctica conocida e incluso asumida por algunos autores, bien abiertamente, bien con algunas reservas ${ }^{62}$. Sin embargo, resulta de todo punto inadmisible y flagrantemente contraria a la LGS.

Cuando los convenios de colaboración prevean la concesión de subvenciones, sencillamente, no pueden suscribirse fuera de los supuestos del art. 22.2 LGS. Es decir, la posibilidad de que una Administración pública firme convenios de colaboración con cualesquiera entidades públicas o privadas con el fin de satisfacer los intereses generales que le han sido confiados no entrańa, en modo alguno, la potestad de conceder directamente subvenciones al margen de lo dispuesto en el ordenamiento jurídico. Ello solo será posible en los casos previstos en el art. 22.2 LGS. Esto es, los convenios de colaboración no son una forma adicional de conceder directamente subvenciones sin acudir al procedimiento de concurrencia competitiva y al margen del art. 22.2 LGS, sino, mucho más modestamente, uno de los instrumentos jurídicos que permitirá su concesión cuando concurra alguno de los supuestos contemplados en dicho artículo ${ }^{63}$.

61 Así lo denunció ya G. Fernández Farreres (2012: 42), tras un pormenorizado análisis del origen y uso de estos convenios de colaboración, concluyendo que se trata de «subvenciones sin más, aunque aparezcan disfrazadas, un tanto burdamente, como participación o colaboración económica de la Administración a la realización o ejecución de actividades privadas».

62 Así, J. C. Laguna de Paz (2005: 350-351) admite expresamente la utilización de convenios administrativos como una forma de crear y conceder directamente subvenciones al margen del art. 22.2 LGS. Por su parte, aunque parece haber modificado posteriormente su postura, J. Pascual García (2007), Las subvenciones públicas, Madrid: BOE (pág. 122), no admite la concesión directa de subvenciones a través de convenios en favor de sujetos privados, salvo que una ley lo autorice expresamente. En cambio, sí admite la concesión directa de subvenciones creadas mediante convenios entre administraciones públicas.

63 Se muestra terminante a este respecto, afirmando la nulidad de los convenios que no respeten el art. 22.2 LGS, Fernández Farreres (2012: 43). En el mismo sentido, Collado Beneyto (2009: 512-513). Modificando su postura anterior, también J. Pascual García (2016: 275) afirma ahora que «el convenio de colaboración [...] no puede considerarse un procedimiento de concesión adicional, sino como un posible instrumento para canalizar las subvenciones de concesión directa». 
Así cabía deducirlo ya de una recta interpretación de la LGS y, muy especialmente, del art. 2.3 RGS. Sin embargo, y para mayor claridad aun, el art. 48.7.1 ${ }^{\circ}$ LRJSP determina ahora expresamente que "cuando el convenio instrumente una subvención, deberá cumplir con lo previsto en la Ley 38/2003, de 17 de noviembre, General de Subvenciones y en la normativa autonómica de desarrollo que, en su caso, resulte aplicable». Es decir, la concesión directa de subvenciones, ya se formalice a través de una resolución administrativa, ya se formalice a través de un convenio, solo será posible en los supuestos expresamente autorizados por el art. 22.2 LGS.

\section{LA CONCESIÓN DE SUBVENCIONES EN CONCURRENCIA COMPETITIVA BASADA ÚNICAMENTE EN CRITERIOS TEMPORALES}

El art. 22.2 LGS impone que la prelación entre las solicitudes se establecerá «de acuerdo con los criterios de valoración previamente fijados en las bases reguladoras y en la convocatoria». Pero la LGS no establece límites ni indicaciones sobre la naturaleza de esos «criterios de valoración» o «criterios objetivos", como los denomina el art. 17.3.e LGS, que deban tenerse en cuenta a efectos de establecer la prelación entre las solicitudes presentadas en el régimen de concurrencia competitiva.

Esto ha dado lugar a que se haya sugerido que las bases reguladoras podrían establecer como único "criterio de valoración» o "criterio objetivo» el momento de la presentación de la solicitud. Es decir, el orden temporal de presentación determinaría la prelación de las solicitudes, de modo que las subvenciones se adjudicarían a los interesados que hubieran presentado en primer lugar sus solicitudes, en una aplicación algo peculiar del principio prior in tempore, potior in iure $e^{64}$. En la práctica, el resultado sería exactamente el mismo que se produciría en un supuesto de concesión directa de subvenciones que tuviera como único límite el crédito presupuestario disponible: todo solicitante que reuniera los requisitos marcados por la norma recibiría la subvención en tanto siguiera existiendo crédito presupuestario suficiente. Es decir, en tanto las solicitudes presentadas antes que la suya, con las cuales no se compara, no hubieran agotado el crédito disponible.

Estas propuestas han encontrado eco en la legislación autonómica. De esta forma, el art. 28 de la Ley 10/2006, de 17 de julio, de Cantabria, bajo el falso título de "procedimiento abreviado» de concesión en concurrencia competitiva dispone que «las subvenciones cuya concesión y justificación se realice mediante la concurrencia en el solicitante de los requisitos establecidos en la normativa

${ }^{64}$ Collado Beneyto (2009: 381-382). 
reguladora, y atendiendo a la prelación temporal de la solicitud hasta el agotamiento del crédito presupuestario, podrán tramitarse por un procedimiento abreviado en el que la propuesta de concesión se formulará al órgano concedente directamente por el órgano instructor, que únicamente deberá comprobar la concurrencia de los requisitos requeridos para conceder la subvención " $"$.

La propuesta es bien ingeniosa y, en apariencia, escrupulosamente respetuosa con la letra de la ley ${ }^{66}$. Sin embargo, difícilmente puede ser más contraria al espíritu de la norma, como se deduce de su contradicción con otros preceptos de la LGS. En efecto, la exposición de motivos $\$ .3$ LGS señala que el procedimiento de concurrencia competitiva, como régimen general de concesión, «debe permitir hacer efectivos los principios inspiradores del otorgamiento de subvenciones previstos en la ley». Tales principios, contenidos en el art. 8.3 LGS, incluyen expresamente el de «eficiencia en la asignación y utilización de los recursos públicos». La eficiencia en la utilización de los recursos públicos en relación con las subvenciones conlleva su concesión a aquellos beneficiarios que en mejor o mayor medida (o a un menor coste, económico o social) pueden satisfacer los intereses generales con su conducta. Tal es el objetivo perseguido por el procedimiento de concurrencia competitiva, que quedaría vaciado de contenido si el único criterio objetivo tenido en cuenta para la concesión de la subvención fuera un elemento ajeno a las cualidades de los solicitantes o a las características de sus proyectos. Por tal motivo, el legislador marca como objetivo del procedimiento de concesión en concurrencia competitiva el realizar una auténtica «evaluación» de los solicitantes (exposición de motivos $\$ .3$, art. 24.3.b y art. 24.4 LGS), objetivo que resulta inalcanzable si el único criterio de valoración es el momento de presentación de la solicitud en registro ${ }^{67}$.

65 En términos muy similares, el art. 17.1.3 Ley Foral 11/2005, de 9 de noviembre, de Subvenciones de Navarra, se refiere a este procedimiento de concesión como «régimen de evaluación individualizada». También el art. 14.3.a Ley 5/2015, de 25 de marzo, de Subvenciones de Aragón, permite en supuestos como este, entre otros, un «procedimiento simplificado de concurrencia competitiva». Y en parecidos términos, pero bajo el nombre de "procedimiento simplificado", se expresa el art. 75.1.2 Decreto Legislativo $1 / 2002$, de 19 de noviembre de 2002, por el que se aprueba el texto refundido de la Ley de Hacienda de Castilla-La Mancha.

66 En este sentido, el mismo Collado Beneyto (2009: 381, nota 4) destaca que el art. 22.2 LGS no impone el «concurso» como forma de otorgamiento, sino la «concurrencia competitiva», de lo que deduce que la "competencia» puede basarse en cualquier tipo de criterio objetivo.

67 Como advierte Fernández Farreres (2012: 37, nota 31), «este sistema, ciertamente, no puede calificarse propiamente como un sistema o procedimiento de concurrencia 
Asimismo, al definir en qué consiste el procedimiento de concesión en concurrencia competitiva, el art. 22.1 LGS señala que «la concesión de las subvenciones se realiza mediante la comparación de las solicitudes presentadas». Sin embargo, si el único criterio que se tiene en cuenta es la fecha de presentación de la solicitud, no es necesaria comparación ninguna entre las solicitudes, siendo posible resolver individualmente a medida que se van presentando (véase art. 14.3.2 ${ }^{\circ}$ de la Ley 5/2015, de 25 de marzo, de Subvenciones de Aragón). De hecho, la mejor prueba de que no hay comparación entre las solicitudes es que no hay por qué esperar a que se presenten todas para resolver a cuál se le concede la subvención.

En consecuencia, debe rechazarse esta modalidad de concesión de subvenciones por resultar contraria a la normativa básica. Nuevamente, la única forma de que resultara aceptable sería cuando concurriese alguna de las circunstancias que permiten la concesión directa de subvenciones recogidas en el art. 22.2 LGS, lo que sí es perfectamente posible ${ }^{68}$.

\section{LA CONCESIÓN DE SUBVENCIONES EN «CONCURRENCIA NO COMPETITIVA»}

Casi desde la aprobación de la LGS, algunos autores han intentado ensayar una tercera vía entre el procedimiento de concurrencia competitiva y el procedimiento de concesión directa. A tal fin, han llamado la atención sobre el hecho de que no toda concurrencia tiene por qué ser, necesariamente, competitiva. Dicho en otros términos, señalan que la "concurrencia pública» debe identificarse con la existencia de una convocatoria pública y la consiguiente presentación de solicitudes. Pero esta convocatoria pública y la necesidad de presentar solicitudes, por sí mismas, no determinarían ni el modo en que se tramitan las solicitudes ni la forma en que, finalmente, se concedan las subvenciones ${ }^{69}$. De

competitiva [...]. Se trata, pues, de un procedimiento rogado, sujeto al tradicional régimen de cola» que, además, ha generado una notable litigiosidad.

68 De manera ejemplar, el art. 22.2 de la Ley 6/2011, de 23 de marzo, de Subvenciones de Extremadura, aun utilizando erróneamente la expresión «convocatoria abierta» (véase art. 59 RGS) prevé que, «excepcionalmente, cuando por la naturaleza o características de la subvención no sea posible su tramitación por el procedimiento de concurrencia competitiva, podrá utilizarse el régimen de concesión directa mediante convocatoria abierta, en virtud del cual las subvenciones podrán irse concediendo conforme se vayan solicitando por los interesados en base a los requisitos o criterios establecidos en las bases reguladoras, siempre que exista crédito presupuestario».

69 Moreu Carbonell (2005: 79-80) y M. Pardo González (2011), «Procedimiento de concesión de subvenciones públicas. Concurrencia y concesión directa», en M. Garcés 
este modo, cabría distinguir entre "concurrencia competitiva» y "concurrencia no competitiva». La concurrencia competitiva se correspondería con la definición ofrecida en el art. 22.1 LGS. La concurrencia no competitiva, por su parte, implicaría la presentación de solicitudes, pero no la comparación entre ellas. En este segundo caso, bastaría la mera comprobación de que los solicitantes cumplen los requisitos exigidos por la norma para, en caso positivo, proceder sin más a la concesión de la subvención.

La construcción ha sido recogida, como no, por la normativa autonómi$\mathrm{ca}^{70}$. Sin embargo, debe destacarse el caso de la Comunidad Autónoma de Andalucía, donde se ha convertido prácticamente en el procedimiento ordinario de concesión de subvenciones ${ }^{71}$.

La categoría resulta, sin embargo, difícilmente justificable y, desde luego, contraria a la LGS. Cuando el legislador básico distingue en la LGS entre procedimiento de concesión en concurrencia competitiva y procedimiento de concesión directa, realiza una summa divisio, una división total, en la que no caben terceras opciones. El criterio diferenciador entre ambas categorías no es, ni remotamente, la existencia de una concurrencia (de una "convocatoria", si se prefiere). Ese dato solo afecta al modo en que se inicia el procedimiento, pero no al modo en que se resuelve, que es lo relevante.

Como ya indicamos en el epígrafe II.1 de este trabajo, el elemento esencial, el criterio que permite distinguir el procedimiento de concurrencia competitiva del procedimiento de concesión directa es la existencia o no de competencia. Es decir, de competición, de rivalidad entre los solicitantes. O bien existe una comparación entre todas las solicitudes y una ordenación entre ellas, atendiendo a su puntuación (concesión en concurrencia competitiva), o bien la concesión se hace depender únicamente del cumplimiento de ciertos requisitos, individualmente considerados en cada solicitud (concesión directa). Tertium non habet.

Sanagustín y A. Palomar Olmeda (coords.), Derecho de las subvenciones y ayudas públicas, Cizur Menor: Aranzadi-Thomson Reuters (págs. 389-390).

70 Un amplio análisis de dicha normativa en Ó. Rodríguez Díaz (2010), «Los procedimientos de concesión de subvenciones públicas. Especial atención a la concurrencia no competitiva y la concesión directa», en Revista CEFlegal CEF, 118 (en especial, págs. 118-122).

71 Curiosamente, el Decreto Legislativo 1/2010, de 2 de marzo, por el que se aprueba el texto refundido de la Ley General de la Hacienda Pública de la Junta de Andalucía, y en cuyo título VII se establece el régimen jurídico de las subvenciones en Andalucía, no hace referencia alguna a la existencia de este procedimiento de concesión en "concurrencia no competitiva». Es el Decreto 282/2010, de 4 de mayo, por el que se aprueba el Reglamento de los procedimientos de concesión de subvenciones de la Administración de la Junta de Andalucía donde se crea y regula dicho procedimiento. 
Lo anterior no niega que pueda haber subvenciones concedidas de manera directa y sin necesidad de concurrencia alguna. Es perfectamente posible y, de hecho, será el caso más habitual de las subvenciones nominativas previstas en el art. 22.2.a LGS. Simplemente es necesario retener que la existencia o no de concurrencia es un dato absolutamente irrelevante para el legislador básico, al que no le preocupa, a estos efectos, cómo se inicia el procedimiento, sino cómo se resuelve.

Lo que no puede existir, por el contrario, es un sistema de concesión de subvenciones en el que exista competencia entre los solicitantes, pero no concurrencia. Es decir, para poder comparar y priorizar las solicitudes es necesario que estas se presenten y, por fuerza, tendrá que abrirse una convocatoria previa. De ahí, seguramente, que el legislador optara por emplear la expresión "concurrencia competitiva», binomio en el que el término importante es el adjetivo "competitiva» y no el sustantivo "concurrencia». Así se deduce, por lo demás, del hecho de que esta expresión vino a sustituir al término "concurso", que era el que había sido empleado por la regulación inmediatamente anterior para identificar este mismo procedimiento (art. 86.6.b.5० Real Decreto Legislativo 1091/1988 TRLGP).

En conclusión, la concurrencia no competitiva, lejos de suponer una tercera vía entre concurrencia competitiva y concesión directa supone, sin ningún lugar a dudas, un supuesto más de concesión directa. Como hemos repetido, el elemento determinante de la concesión directa es que la decisión de concesión a un beneficiario se adopta por la Administración (o, en su caso, el legislador) sin atender a las circunstancias que puedan concurrir en otros posibles beneficiarios. El elemento esencial es que no existe competencia. Pero la existencia o inexistencia de concurrencia, de que varios sujetos concurran al procedimiento, es de todo punto irrelevante.

En consecuencia, una vez más, las subvenciones concedidas a través de la llamada «concurrencia no competitiva» solo serán conformes a derecho cuando puedan reconducirse a alguno de los tres supuestos previstos en el art. 22.2 $\mathrm{LGS}^{72}$. Al margen de estos supuestos, solo cabría aceptar la legalidad de las subvenciones concedidas mediante procedimientos de «concurrencia no competitiva» cuando se trate de una "concurrencia no competitiva» de facto. Es

72 En este mismo sentido, Frías López (2005), al analizar el art. 2.e Decreto 222/1998 de la Comunidad de Madrid, que ya preveía que la concesión de ayudas podía hacerse mediante un procedimiento de "concurrencia no competitiva", señala, con acierto, que el precepto debía entenderse derogado y no aplicable tras la aprobación de la LGS por incompatibilidad con el art. 22 LGS, salvo cuando resultara compatible con alguno de los supuestos de concesión directa previstos en el art. 22.2 LGS. 
decir, cuando se cumpla el supuesto previsto en el art. 55.1.2 ${ }^{\circ} \mathrm{RGS}$ al que nos referimos más atrás.

\section{CONCLUSIONES}

El legislador básico fue muy estricto al establecer en la LGS los supuestos en los que las administraciones públicas pueden acudir al procedimiento de concesión directa de subvenciones, limitándolos, en la práctica, a tres casos. Esta opción legislativa no fue casual, sino la respuesta a una situación previa en la que las administraciones gozaban de amplias potestades discrecionales para el establecimiento y concesión de subvenciones, con las que no siempre se garantizaba el pleno respeto a los principios de publicidad, igualdad, objetividad o eficiencia en la utilización y asignación de los recursos públicos. El nuevo régimen jurídico supuso un indudable avance, pero su análisis revela lagunas, contradicciones y carencias que han quedado puestas de manifiesto y que deberían ser objeto de enmienda.

Ahora bien, del estudio conjunto de todo nuestro ordenamiento se desprende que las principales grietas del régimen jurídico de la concesión directa de subvenciones no se encuentran en la LGS, sino en la normativa autonómica de subvenciones, donde se ha dado rienda suelta a una admirable, aunque censurable, creatividad. Es en este ámbito, sin duda, en el que deberían centrarse los esfuerzos de reforma. Por lo demás, una vez aclarado por las SSTC 130 y 135/2013, de 4 y 6 de junio, el alcance de las competencias básicas del Estado en el régimen jurídico de las subvenciones, tales reformas no se deberían hacer esperar. Todo ello redundaría, en definitiva, en una mayor coherencia, previsibilidad y confianza en la actuación de las administraciones públicas en materia de subvenciones. Aunque, incluso en ese caso, nunca deban olvidarse las palabras de Laoconte. 